\title{
Mutual regulation between chicken telomerase reverse transcriptase and the Wnt/ $\beta$-catenin signalling pathway inhibits apoptosis and promotes the replication of ALV-J in LMH cells
}

Yong Xiang ${ }^{1}$, Yun Yu ${ }^{1}$, Qingbo Li ${ }^{1}$, Zeng Jiang ${ }^{1}$, Jinqun Li ${ }^{1}$, Canxin Liang ${ }^{1}$, Jian Chen ${ }^{1}$, Yu Li ${ }^{1}$, Xiaoyan Chen ${ }^{1}$ and Weisheng $\mathrm{CaO}^{1,2,3,4,5^{*}}$ (D)

\begin{abstract}
This study aimed to explore the mutual regulation between chicken telomerase reverse transcriptase (chTERT) and the Wnt/ $\beta$-catenin signalling pathway and its effects on cell growth and avian leukosis virus subgroup J (ALV-J) replication in LMH cells. First, LMH cells stably overexpressing the chTERT gene (LMH-chTERT cells) and corresponding control cells (LMH-NC cells) were successfully constructed with a lentiviral vector expression system. The results showed that chTERT upregulated the expression of $\beta$-catenin, Cyclin D1, TCF4 and c-Myc. chTERT expression level and telomerase activity were increased when cells were treated with $\mathrm{LiCl}$. When the cells were treated with ICG001 or IWP-2, the activity of the Wnt/ $\beta$-catenin signalling pathway was significantly inhibited, and chTERT expression and telomerase activity were also inhibited. However, when the $\beta$-catenin gene was knocked down by small interfering RNA (siRNA), the changes in chTERT expression and telomerase activity were consistent with those in cells treated with ICG001 or IWP-2. These results indicated that chTERT and the Wnt/ $\beta$-catenin signalling pathway can be mutually regulated. Subsequently, we found that chTERT not only shortened the cell cycle to promote proliferation but also inhibited apoptosis by downregulating the expression of Caspase 3, Caspase 9 and BAX; upregulating BCL-2 and BCL-X expression; and promoting autophagy. Moreover, chTERT significantly enhanced the migration ability of LMH cells, upregulated the protein and mRNA expression of ALV-J and increased the virus titre. ALV-J replication promoted chTERT expression and telomerase activity.
\end{abstract}

Keywords: chicken telomerase reverse transcriptase, Wnt/ $\beta$-catenin signalling pathway, cell proliferation, apoptosis, avian leukosis virus subgroup J

*Correspondence: caoscauvet@163.com

${ }^{1}$ College of Veterinary Medicine, South China Agricultural University, Guangzhou 510642, China

Full list of author information is available at the end of the article

\section{Introduction}

Telomerase is a ribonucleoprotein enzyme that adds tandem (TTAGGG)n repeats to the ends of chromosomes in most eukaryotes [1]. The structure of chicken telomerase, which consists of chicken telomerase reverse transcriptase (chTERT), telomerase RNA component and telomerase-associated protein, is similar to that of human telomerase [2, 3]. Telomerase activation is considered a original author(s) and the source, provide a link to the Creative Commons licence, and indicate if changes were made. The images or other third party material in this article are included in the article's Creative Commons licence, unless indicated otherwise in a credit line to the material. If material is not included in the article's Creative Commons licence and your intended use is not permitted by statutory regulation or exceeds the permitted use, you will need to obtain permission directly from the copyright holder. To view a copy of this licence, visit http://creativecommons.org/licenses/by/4.0/. The Creative Commons Public Domain Dedication waiver (http://creativeco mmons.org/publicdomain/zero/1.0/) applies to the data made available in this article, unless otherwise stated in a credit line to the data. 
key step in cell carcinogenesis, and telomerase is one of the most commonly used molecular markers for a wide range of malignant tumours [4-6]. Studies have shown that human telomerase reverse transcriptase (hTERT) gene expression is the core determinant of telomerase activity, and overexpression of the hTERT gene is found in approximately $90 \%$ of human malignant tumours [7-9]. hTERT promoter activity is usually regulated by a variety of transcription factors $(\beta$-catenin, NF- $\mathrm{KB}$ and $\mathrm{c}-\mathrm{Myc})$, chromatin remodelling, and epigenetic methylation [10-16].

Avian leukosis is an infectious tumour caused by avian leukosis viruses (ALVs) belonging to the Alpharetrovirus genus of the family Retroviridae that affects poultry [17]. Chickens infected with exogenous ALV may suffer from decreased performance and immunosuppression, leading to tumour formation and even death $[18,19]$. Avian leukosis is one of the most important diseases endangering the healthy development of poultry in China. Based on the specific envelope glycoprotein (gp85) expressed, ALV in naturally infected chicken flocks can be divided into seven subgroups (A, B, C, D, E, J and K). Endogenous subgroup $\mathrm{E}$ viruses with little to no pathogenicity are present in nearly all chicken lines, while the viruses of the other subgroups are exogenous and pathogenic. Subgroup $A$ and $B$ viruses mainly cause lymphocytic leukaemia and myeloid leukosis in field flocks, while flocks naturally infected with subgroup $C$ and $D$ viruses are rarely observed in the field. ALV subgroup J (ALV-J) is the most pathogenic to chickens, and it is more likely than viruses in the other ALV subgroups to cause tumours in chickens [20-22]. Yang et al. found ALV integration in the chTERT promoter/enhancer region in B cell lymphomas, suggesting that this is a common integration site, and chTERT expression was elevated by ALV integration [23]. Moreover, the chTERT gene was identified as a common insertion site in myeloid leukosis caused by ALV-J, and the gene expression of chTERT, a putative driver for oncogene activation, was significantly upregulated in tumour samples compared to control samples [24]. However, it is not clear whether chTERT affects ALV-J replication and what effect ALV-J has on chTERT.

The Wnt signalling pathway is a complex signalling pathway related to cell growth and development. Abnormal activation of Wnt is closely related to the development of cardiovascular disease, hepatic fibrosis and cancer $[25,26]$. The Wnt/ $\beta$-catenin signalling pathway, which is considered the most common Wnt signalling pathway, plays critical roles in various cellular functions, including cell proliferation, differentiation, migration and apoptosis [27-29]. The significance of this pathway is exemplified by evidence that both the overexpression and underexpression of target genes involved in this pathway result in various diseases. Appropriate regulation of the Wnt/ $\beta$-catenin signalling pathway is key for cells to carry out their normal functions $[28,30]$. The Wnt/ $\beta$-catenin signalling pathway has been implicated in the transcriptional reactivation of hTERT in cancer cells; transient activation of Wnt/ $\beta$ catenin induces hTERT mRNA expression and elevates telomerase activity in different cell lines [12, 31-33]. Blockade of Wnt/ $\beta$-catenin signalling or regulation of chTERT activation may be effective therapeutic strategies for decreasing apoptotic events in cancer cells. However, whether Wnt/ $\beta$-catenin impacts chTERT remains to be investigated. Therefore, in this study, in vitro models were used to assess chTERT expression and Wnt/ $\beta$-catenin signalling in the $\mathrm{LMH}$ cell line and to explore the effects of chTERT and Wnt/ $\beta$-catenin on cell proliferation, apoptosis, and migration and ALV-J replication to lay a theoretical foundation for further elucidating the mechanism of chTERT in the tumorigenic effect of ALV-J.

\section{Materials and methods Antibodies}

Anti- $\beta$-catenin and anti-c-Myc primary antibodies were purchased from Santa Cruz Biotechnology (Santa Cruz, CA, USA). Anti-TCF4 and anti-Cyclin D1 primary antibodies were purchased from Affinity Biosciences, Ltd. (USA). An anti-GAPDH primary antibody was purchased from Abcam, Inc. (UK). An anti-HA tag antibody was purchased from Invitrogen, Thermo Fisher Scientific, Inc. (California, USA). An anti-Ki67 (chicken) antibody was purchased from GeneTex, Inc. (USA). A goat anti-rabbit IgG (FITC) secondary antibody and a goat anti-mouse IgG (FITC) secondary antibody were purchased from LI-COR Biosciences, Ltd. (Nebraska, USA). Mouse monoclonal antibodies (G2.3) against the gp85 protein of ALV-J were donated by Avian Disease and Oncology Laboratory (USA).

\section{Cell culture and viruses}

The chicken hepatocellular carcinoma cell line LMH and the 293T cell line were kindly provided by Professor Ming Liao of South China Agricultural University. The chicken fibroblast cell line DF-1 was maintained in our laboratory. LMH, 293T and DF-1 cells were cultured in DMEM/F12 (Gibco, Thermo Fisher Scientific, Inc., USA) and DMEM (Gibco, Thermo Fisher Scientific, Inc.) supplemented with $10 \%$ foetal bovine serum (FBS) at $37{ }^{\circ} \mathrm{C}$ with $5 \% \mathrm{CO}_{2}$. The ALV-J CHN06 strain was maintained in our laboratory. 


\section{Construction of a chTERT gene expression plasmid and a stable overexpression cell line}

The full-length chTERT coding region was amplified by RT-PCR from broiler embryos (4-7 days) as two overlapping fragments (chTERT-T1 and chTERT-T2) using Phanta ${ }^{\circledR}$ Max Super-Fidelity DNA Polymerase (Vazyme, Nanjing, China). Primers were designed according to relevant literature [34], and the sequences are shown in Table 1. The PCR product of chTERT-T2 was amplified again to add a linker and an HA tag to the end of the DNA to generate chTERT-T2-HA. The reaction conditions were as follows: 1 cycle of $95{ }^{\circ} \mathrm{C}$ for $5 \mathrm{~min}$; 35 cycles of $95{ }^{\circ} \mathrm{C}$ for $45 \mathrm{~s}, 62{ }^{\circ} \mathrm{C}$ for $30 \mathrm{~s}$ and $72{ }^{\circ} \mathrm{C}$ for $150 \mathrm{~s}$; and 1 cycle of $72{ }^{\circ} \mathrm{C}$ for $8 \mathrm{~min}$. The annealing temperature was adjusted according to the Tm value of the primer. Since there is no commercially available antibody for chTERT, the HA tag was used to measure chTERT protein levels. Then, the chTERT-T1 and chTERT-T2-HA fragments were ligated into the pLV$\operatorname{sfGFP}(2 \mathrm{~A})$ (puromycin) lentiviral expression vector at the Xba I and Xho I sites with a ClonExpress ${ }^{\circledR}$ Ultra One Step Cloning Kit (Vazyme, Nanjing, China) through homologous recombination to generate pLVchTERT-HA. Lentiviral transfection and screening were performed according to the user manual for the lentiviral gene transfer and expression system (Inovogen, Wuhan, China). Briefly, the pLV-chTERT-HA plasmid was transfected into 293T cells using PolyJet $^{\text {TM }}$ In Vitro DNA transfection reagent (SignaGen, Maryland, USA). At 48 to $72 \mathrm{~h}$ post-transfection, the lentivirus in the supernatant was harvested, filtered through a $0.45-\mu \mathrm{m}$ filter and used to infect LMH cells. After LMH cells were infected with lentivirus containing chTERT or empty control for $48 \mathrm{~h}$, puromycin was added to kill uninfected cells. Finally, LMH cells stably overexpressing the chTERT gene (LMH-chTERT cells) or control (LMH-NC cells) were obtained.

\section{Cell treatment}

To inhibit the expression of Wnt/ $\beta$-catenin and chTERT, cells were transfected with small interfering RNA (siRNA) targeting $\beta$-catenin (si- $\beta$-catenin, $5^{\prime}$-GCUGGU GGGAUGCAAGCUUTT- ${ }^{\prime}$, 5 '-AAGCUUGCAUCC CACCAGCTT-3') or chTERT (si-chTERT, 5'-GCA UGGAACCUCCUGGCAUTT- ${ }^{\prime}$, 5'-AUGCCAGGA GGUUCCAUGCTT-3') or a nonspecific siRNA (si-NC, 5'-ACGUGACACGUUCGGAGAATT-3', 5'-UUCUCC GAACGUGUCACGUTT- $\left.{ }^{\prime}\right) \quad(10 \mu \mathrm{mol} / \mathrm{L}) \quad$ (Shanghai GenePharma Company). Cells plated in 12-well plates (100 000 cells/well) were transfected with siRNA using siRNA-Mate Transfection Reagent (GenePharma, Shanghai, China). In addition, ICG001 and IWP-2 (Beyotime, Shanghai, China) and LiCl (Sigma-Aldrich, St. Louis, Missouri, USA) were added directly to the cell culture medium to inhibit and activate $\mathrm{Wnt} / \beta$-catenin signalling pathway activity, respectively [35-37]. After treatment for at least $24 \mathrm{~h}$, cell viability and mRNA and protein expression were assessed by MTT assays, RT-PCR and Western blotting, respectively.

\section{MTT assay}

Cytotoxicity was measured using the MTT assay with an Enhanced Cell Counting Kit-8 (Beyotime). The assay was performed according to the user manual. Briefly, LMH cells were plated in 96-well plates at a density of $1 \times 10^{4}$ cells/well in $200 \mu \mathrm{L}$ medium for $12 \mathrm{~h}$ and then treated with ICG001, IWP-2, $\mathrm{LiCl}$ and siRNA at different concentrations. After $72 \mathrm{~h}, \mathrm{CCK}-8$ reagent was added to the cells in the plate, the cells were incubated at $37^{\circ} \mathrm{C}$ for $2 \mathrm{~h}$, and the absorption was measured at $450 \mathrm{~nm}$

Table 1 Primers used for gene cloning and expression analysis

\begin{tabular}{ll}
\hline Primer $^{\text {name }}{ }^{\text {a }}$ & Primer sequence $\mathbf{5}^{\prime} \mathbf{- 3}^{\prime} \mathbf{)}$ \\
\hline chTERT-T1-F (Xba l) & CTCTACTAGAGGATCtctagaCGTGGGGCCCGCTGCACGGCAGCG \\
chTERT-T1-R & ATACGCAGTCATTCACTCTCATCTTCCACATC \\
chTERT-T2-F & GCCATAACAAATGCCGGTTCTTTAAAAACGTG \\
chTERT-T2-R & GGGGTACCAGACCTTCATCCCTTAGTCCAG \\
chTERT-T2-linker-F & GTGATCCGCTCCTCAGGGAGCTGCTCAGGCAGCACAGCA \\
chTERT-T2-linker-R & GCCACTGGCAGGTGTATGGCTTGGGGG \\
chTERT-T2-HA-F & CGATCCGCCACCGCCAGAGCCACCTCCGCCTGAACCGCC \\
chTERT-T2-HA-R & TCCACCGGTACCGTCCAGTATAGTTTGAAAT \\
(Xho I) & GTGATCCGCTCCTCAGGGAGCTGCTCAGGCAGCACAGCA \\
\hline
\end{tabular}

${ }^{\mathrm{a}} \mathrm{F}$ : forward primer, R: reverse primer

${ }^{b}$ The lowercase letters indicate restriction sites 
using a microplate reader (BioTek, Vermont, USA). Relative absorbance was calculated according to the following formula: cell viability $=\left(\mathrm{OD}_{\text {treated }}-\mathrm{OD}_{\text {blank }}\right) /$ $\left(\mathrm{OD}_{\text {untreated }}-\mathrm{OD}_{\text {blank }}\right)$, where $\mathrm{OD}$ is the optical density at $450 \mathrm{~nm}$.

\section{Real-time fluorescence quantitative PCR (RT-PCR)}

Total RNA was extracted from LMH cells by using TRIzol reagent (Fastagen Biotech, Shanghai, China) according to the manufacturer's recommendations. First-strand cDNA was synthesized from $500 \mathrm{ng}$ of total RNA template with random primers using a PrimeScript RT Reagent kit (TaKaRa, Japan). RT-PCR was performed using Hieff ${ }^{\circledR}$ qPCR SYBR Green Master Mix (YEASEN, Shanghai, China) on the CFX96 ${ }^{\mathrm{TM}}$ Real-time PCR System (Bio-Rad, California, USA). Expression levels were quantified using the $2^{-\Delta \Delta \mathrm{Ct}}$ method and normalized to GAPDH expression. All the primer sequences are shown in Table 2.

\section{Western blotting}

Protein was extracted from LMH cells using Fierce RIPA Lysis Buffer (Beyotime) following the manufacturer's instructions. Briefly, equal amounts of total protein were separated by SDS-polyacrylamide gel electrophoresis (SDS-PAGE) (Beyotime) and then transferred onto a polyvinylidene difluoride (PVDF) membrane. The membranes were immunoblotted with primary antibodies at $4{ }^{\circ} \mathrm{C}$ overnight, followed by incubation with a fluorescein isothiocyanate-conjugated secondary antibody at $37{ }^{\circ} \mathrm{C}$ for one hour. Finally, the blots were scanned using an Odyssey Infrared Imaging System (LI-COR, Nebraska, USA).

\section{Telomerase activity assay}

Telomerase activity was measured by the telomeric repeat amplification protocol (TRAP), which was conducted with the TeloTAGGG Telomerase PCR ELISA Kit (Sigma-Aldrich) following the manufacturer's protocol. A total of $2 \times 10^{5}$ cells were transferred to an Eppendorf tube and centrifuged. The pellet was resuspended in lysis buffer $(200 \mu \mathrm{L})$ and incubated for $30 \mathrm{~min}$ on ice, and then, the supernatant was collected and transferred to a fresh tube. A total of $25 \mu \mathrm{L}$ reaction mixture was transferred to an amplification tube, and $23 \mu \mathrm{L}$ PCR-grade water and 2 $\mu \mathrm{L}$ sample or positive (293T cell lysate) or negative (DF-1 cell lysate) control were added to obtain a $50-\mu \mathrm{L}$ PCR system. Amplification was performed on a PCR instrument (Applied Biosystems, Foster City, CA, USA) under the following conditions: 1 cycle of $25{ }^{\circ} \mathrm{C}$ for $20 \mathrm{~min}$; 1 cycle of $94{ }^{\circ} \mathrm{C}$ for $5 \mathrm{~min} ; 30$ cycles of $94{ }^{\circ} \mathrm{C}$ for $30 \mathrm{~s}, 50{ }^{\circ} \mathrm{C}$ for $30 \mathrm{~s}$ and $72{ }^{\circ} \mathrm{C}$ for $90 \mathrm{~s}$; and 1 cycle of $72{ }^{\circ} \mathrm{C}$ for $10 \mathrm{~min}$. Then, $20 \mu \mathrm{L}$ denaturation reagent and $5 \mu \mathrm{L}$ amplification
Table 2 Primers used for real-time fluorescence quantitative PCR

\begin{tabular}{|c|c|c|}
\hline Gene & Primer sequence $\left(5^{\prime}-3^{\prime}\right)$ & Reference \\
\hline \multirow[t]{2}{*}{ chTERT } & F: GTAAGACTAAGCCGTGTTGTTG & {$[23]$} \\
\hline & R: CTCCCGAATACTGAAGAGC & \\
\hline \multirow[t]{2}{*}{$\beta$-catenin } & F: GCCCTGCTCAACAAGACAAA & {$[54]$} \\
\hline & R: CTGACAACACCTTCAGCACC & \\
\hline \multirow[t]{2}{*}{ Cyclin D1 } & F:TCGTTCGAACCCCTCAAGAA & {$[54]$} \\
\hline & R: GCGGTCAGAGGAATCGTTTC & \\
\hline \multirow[t]{2}{*}{ TCF4 } & F: CCCTTACCCAACAGCTCTGA & {$[54]$} \\
\hline & R: CTATGGCCGGATGAGGGATT & \\
\hline \multirow[t]{2}{*}{ c-Myc } & F: AGCGACTCGGAAGAAGAACAAG & {$[55]$} \\
\hline & R: ATCGACTTCGCTTGCTCAGACT & \\
\hline \multirow[t]{2}{*}{$\mathrm{BCL}-2$} & F: ATCGTCGCCTTCTTCGAGTT & {$[49]$} \\
\hline & R: ATCCCATCCTCCGTTGTCCT & \\
\hline \multirow[t]{2}{*}{ BAX } & F:TGGATTCTCACAGTAGGAGGATG & {$[49]$} \\
\hline & R: CGTAGACCTTGCGGATAAAGC & \\
\hline \multirow[t]{2}{*}{$B C L-X$} & F: CTTTCAGCGACCTCACCTC & {$[49]$} \\
\hline & R: ACAATGCGTCCCACCAGT & \\
\hline \multirow[t]{2}{*}{ Caspase 9} & F: CCGAAGGAGCAAGCACG & {$[56]$} \\
\hline & R: AGGTTGGACTGGGATGGAC & \\
\hline \multirow[t]{2}{*}{ Caspase 3} & F: CATCTGCATCCGTGCCTGA & {$[56]$} \\
\hline & R: CTCTCGGCTGTGGTGGTGAA & \\
\hline \multirow[t]{2}{*}{ ALV-J } & F:TGTGTGCGTGGTTATTATTTC & {$[57]$} \\
\hline & R: AATGGCGAGGTCGCTGACTGC & \\
\hline \multirow[t]{2}{*}{ GAPDH } & F: GGAAAGTCATCCCTGAGCTG & {$[23]$} \\
\hline & R: GGTCAACAACAGAGACATTGG & \\
\hline
\end{tabular}

products were added sequentially to the tube, and the mixture was incubated for $10 \mathrm{~min}$ at room temperature. Hybridization buffer $(225 \mu \mathrm{L})$ was added, followed by thorough mixing, and $100 \mu \mathrm{L}$ of the mixture was transferred to each microplate well and incubated for $2 \mathrm{~h}$ at $37{ }^{\circ} \mathrm{C}$. After 3 washes, anti-DIG-POD working solution $(100 \mu \mathrm{L})$ was added, and the samples were incubated for $30 \mathrm{~min}$ at room temperature. Then, after 5 washes, TMB substrate solution $(100 \mu \mathrm{L})$ was added and incubated for $15 \mathrm{~min}$ at room temperature. Finally, $100 \mu \mathrm{L}$ top reagent was added, and the absorbance at $450 \mathrm{~nm}$ was measured within $15 \mathrm{~min}$.

\section{Flow cytometry}

Cell proliferation, apoptosis and cell cycle were analysed by flow cytometry using the BeyoClick ${ }^{\mathrm{TM}}$ EdU Cell Proliferation Kit with Alexa Fluor 647 (Beyotime), Annexin V-APC Apoptosis Analysis Kit (Sungene Biotech, Tianjin, China) and Cell Cycle Kit (Beyotime), respectively, according to the manufacturer's protocol. Cells were acquired on a CytoFLEX flow cytometer (Beckman 
Coulter, Florida, USA), and data were analysed by FlowJo software (Tree Star, Inc., Ashland, OR, USA).

\section{Immunofluorescence analysis}

Apoptosis was analysed by immunofluorescence using a One Step TUNEL Apoptosis Assay Kit (Beyotime) according to the manufacturer's protocol. Cell proliferation was also analysed by Ki67 immunofluorescence. Seventy-two hours after LMH-chTERT and LMH-NC cells were plated in 6 -well plates at a density of $1 \times 10^{5}$ cells/ well, the cells were fixed with $3 \%$ formaldehyde and $2 \%$ sucrose in PBSA and then permeabilized with $0.1 \mathrm{M}$ glycine. The cells were blocked with $2 \%$ normal goat serum and $0.4 \%$ Triton X-100 in PBSA for $30 \mathrm{~min}$ and incubated overnight with primary antibody. After being washed with $0.2 \%$ Triton X-100 in PBSA, the cells were incubated with Cy3-labelled goat anti-rabbit IgG secondary antibody, and DAPI was used for nuclear visualization. Images were captured using a Nikon Ti2 microscope and Nikon camera.

\section{Transmission electron microscopy (TEM)}

LMH cells were plated into 6-well cell culture plates, incubated for $24 \mathrm{~h}$, harvested, and fixed in $2.5 \%$ glutaraldehyde for $24 \mathrm{~h}$ at $4{ }^{\circ} \mathrm{C}$. Subsequently, the cells were rinsed with buffer, fixed with citric acid, and dehydrated in a series of ethanol solutions. Then, the cells were permeabilized in different ratios of ethanol: resin and embedded in pure resin, which was polymerized at $70{ }^{\circ} \mathrm{C}$. The stained cells were visualized using a transmission electron microscope (Hitachi, Ltd., Japan) to observe various structures within the cells.

\section{Wound healing assay}

Cell culture inserts (Ibidi, Martinsried, Germany) were placed in 6-well plates, and LMH cells were plated on the inserts. After the cell density reached $100 \%$, the inserts were removed, a wound was created, the supernatant was discarded, and Opti-MEM (Gibco, California, USA) without serum was added to culture the cells. After 24 and $48 \mathrm{~h}$, the cells were imaged with a Nikon Eclipse Ti2 microscope, and the pixel area of the wound gap was calculated using ImageJ v1.49 (NIH, USA). The migration rate (MR) was calculated as (initial pixel area $(0 \mathrm{~h})$-terminal pixel area $(24 \mathrm{~h}$ or $48 \mathrm{~h})) /$ initial pixel area $(0 \mathrm{~h}) \times 100 \%$.

\section{Enzyme-linked immunosorbent assay (ELISA) for ALV p27} Cells infected with ALV-J CHN06 at a multiplicity of infection (MOI) of approximately 0.1 were incubated at $37{ }^{\circ} \mathrm{C}$ with $5 \% \mathrm{CO}_{2}$ for 7 days. Then, ALV group-specific p27 antigen levels in the cell culture supernatant were measured with an Avian Leukosis Virus Antigen Test Kit (IDEXX Laboratories Pty., Ltd., Westbrook, USA) according to the manufacturer's protocol. Briefly, samples and positive and negative controls $(100 \mu \mathrm{L})$ were added to the wells of ELISA plates, incubated at room temperature for $60 \mathrm{~min}$, and then washed three to five times with $350 \mu \mathrm{L} /$ well washing buffer. Then, $100 \mu \mathrm{L}$ HRP-conjugated rabbit antibody against p27 was added to all the wells, and the plate was incubated for another $60 \mathrm{~min}$. After 3-5 washes, $100 \mu \mathrm{L}$ substrate solution was added for colour development for $15 \mathrm{~min}$, and the reaction was stopped by adding $100 \mu \mathrm{L}$ stop solution to each well. The absorbance at $650 \mathrm{~nm}$ was measured using a microplate reader (BioTek). The expression level of ALV p27 was determined by calculating the S/P value: [(mean sample OD) - (mean negative control OD)]/[(mean positive control OD) - (mean negative control OD)].

\section{$\mathrm{TCID}_{50}$ assay}

The $\mathrm{TCID}_{50}$ assay was used to evaluate the virus titre. DF-1 cells were cultured in 96-well plates at a density of $4 \times 10^{4}$ cells per well. A tenfold serially diluted virus sample was added to each well in a volume of $100 \mu \mathrm{L}$ (eight replicates for each sample) and incubated for $2 \mathrm{~h}$. Then, the supernatant was discarded, fresh DMEM containing 1\% FBS was added, and the cells were incubated for 7 continuous days at $37^{\circ} \mathrm{C}$ in $5 \% \mathrm{CO}_{2}$. ELISAs for ALV p27 were performed. The $\mathrm{TCID}_{50}$ was calculated using the Reed-Muench method.

\section{Statistical analysis}

All the results are presented as the mean \pm standard deviation. Statistical analysis was performed by Student's $t$ test using GraphPad 5 software. A $p$ value of $<0.05$ was considered significant. ${ }^{*}, * *, * * *$ and ${ }^{* * * * * *}$ indicate $p$ values less than $0.05,0.01,0.001$ and 0.0001 , respectively.

\section{Results \\ Cloning of the chTERT gene}

The chTERT gene, which is approximately $4000 \mathrm{bp}$ in length, was obtained by PCR as described in the Methods. The results of agarose gel electrophoresis of the amplification products for the chTERT-T1, chTERT-T2 and chTERT-T2-HA fragments and the double restriction digestion of the pLV-chTERT-HA plasmid are shown in Additional file 1. The recombinant plasmids were sent to Sangon Biological (Shanghai, China) for sequencing, and the results showed that the full-length coding sequence of chTERT was $4097 \mathrm{bp}$ long and was predicted to encode a protein of 1346 amino acids (aa). The aa sequence of the protein was nearly identical to that of the Gallus gallus 
TERT sequence [GenBank: NM_001031007.1] except for one transition mutation (a V-I mutation at aa 326 and an $\mathrm{R}-\mathrm{H}$ mutation at aa 384 ).

\section{Stable overexpression of the chTERT gene in LMH cells} The pLV-chTERT-HA and pLV-NC plasmids were used to infect LMH cells. After repeated screening with puromycin, LMH cells stably overexpressing the chTERT gene (LMH-chTERT cells) and negative control cells (LMHNC cells) were obtained. The results showed that the mRNA and protein expression levels of chTERT were significantly higher in LMH-chTERT cells than in control cells (Figure 1A; $p<0.0001$ ). Although LMH cells were telomerase positive, the expression level of chTERT was extremely low. In addition, telomerase activity in LMHchTERT cells was significantly higher than that in control cells (Figure 1B; $p<0.01$ ) but lower than that in $293 \mathrm{~T}$ cells, which were regarded as positive controls. DF-1 cells, which do not exhibit telomerase activity, were used as negative controls.

\section{Cytotoxic effects of LiCl, ICG001, IWP-2 and siRNA on LMH cells}

To determine the concentration range at which the investigated inhibitors and siRNAs suppress $\beta$-catenindependent gene or chTERT gene expression without markedly affecting cell viability, the cytotoxic effects of Wnt/ $\beta$-catenin signalling pathway inhibitors (ICG001 and IWP-2) and siRNAs (si- $\beta$-catenin and si-chTERT) were assessed by MTT assays. The cytotoxicity of a Wnt/ $\beta$-catenin signalling pathway activator $(\mathrm{LiCl})$ was also tested. For functional testing, the cells were incubated with an inhibitor or activator at different concentrations for 24,36 , or $72 \mathrm{~h}$. Similarly, LMH cells were transfected with different concentrations of siRNA for 24,36 , or $72 \mathrm{~h}$. Over a wide range of concentrations, ICG001, IWP$2, \mathrm{LiCl}$ and siRNAs decreased cell viability in a dosedependent manner. The reduction in LMH cell viability was not significantly different from that observed in the control group when ICG001 was administered at concentrations $\leq 5 \mu \mathrm{M}$, time had no obvious influence on cell viability at these concentrations (Figure $2 \mathrm{~A}$ ), and similar results were obtained with IWP-2 (Figure 2B). At a concentration of $\geq 20.0 \mu \mathrm{M}, \mathrm{LiCl}$ significantly decreased the viability of LMH cells; however, at 5.0 and $10.0 \mathrm{mM}$, $\mathrm{LiCl}$ significantly increased cell viability, and the effect of $5 \mathrm{mM} \mathrm{LiCl}$ was stronger than that of $10 \mathrm{mM} \mathrm{LiCl}$ (Figure $2 \mathrm{C}$ ). In addition, both $\beta$-catenin siRNA and chTERT siRNA exhibited significant cytotoxicity at concentrations $\geq 75 \mathrm{nM}$ (Figures 2D and E). Therefore, the optimal concentrations of ICG001, IWP-2, $\mathrm{LiCl}$ and siRNAs were $5 \mu \mathrm{M}, 5 \mu \mathrm{M}, 5 \mathrm{mM}$ and $50 \mathrm{nM}$, respectively; these concentrations were used in subsequent experiments.

\section{chTERT activated the $\mathrm{Wnt} / \beta$-catenin signalling pathway overexpression}

The Western blot and RT-PCR results showed that chTERT significantly increased $\beta$-catenin protein expression, which was higher in LMH-chTERT cells than in LMH-NC cells. The overexpression of chTERT also significantly increased the expression of downstream target genes, such as cyclin D1, the transcription factor TCF4

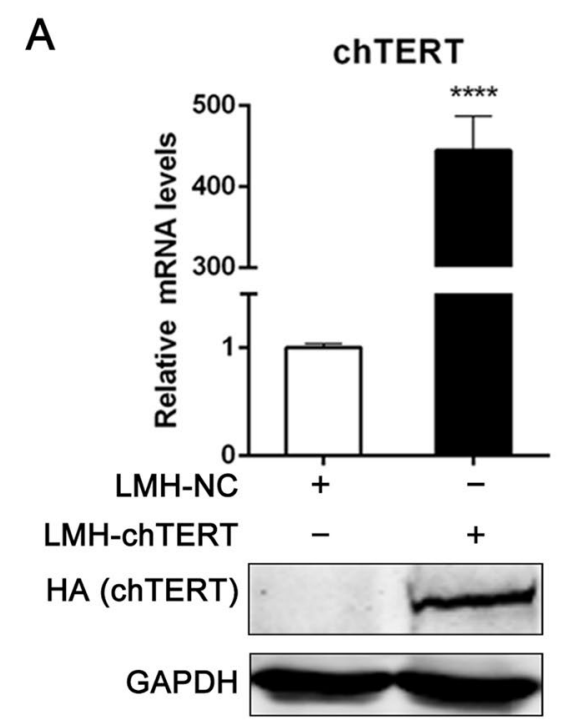

B

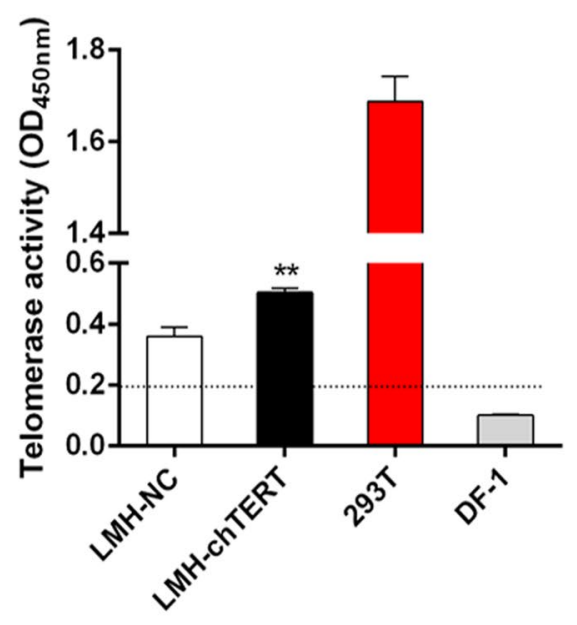

Figure 1 Stable overexpression of the chTERT gene in LMH cells. A The MRNA and protein levels of chTERT. B Analysis of telomerase activity. Cells with an $\mathrm{OD}_{450 \mathrm{~nm}}$ greater than or equal to 0.2 were considered telomerase positive. 

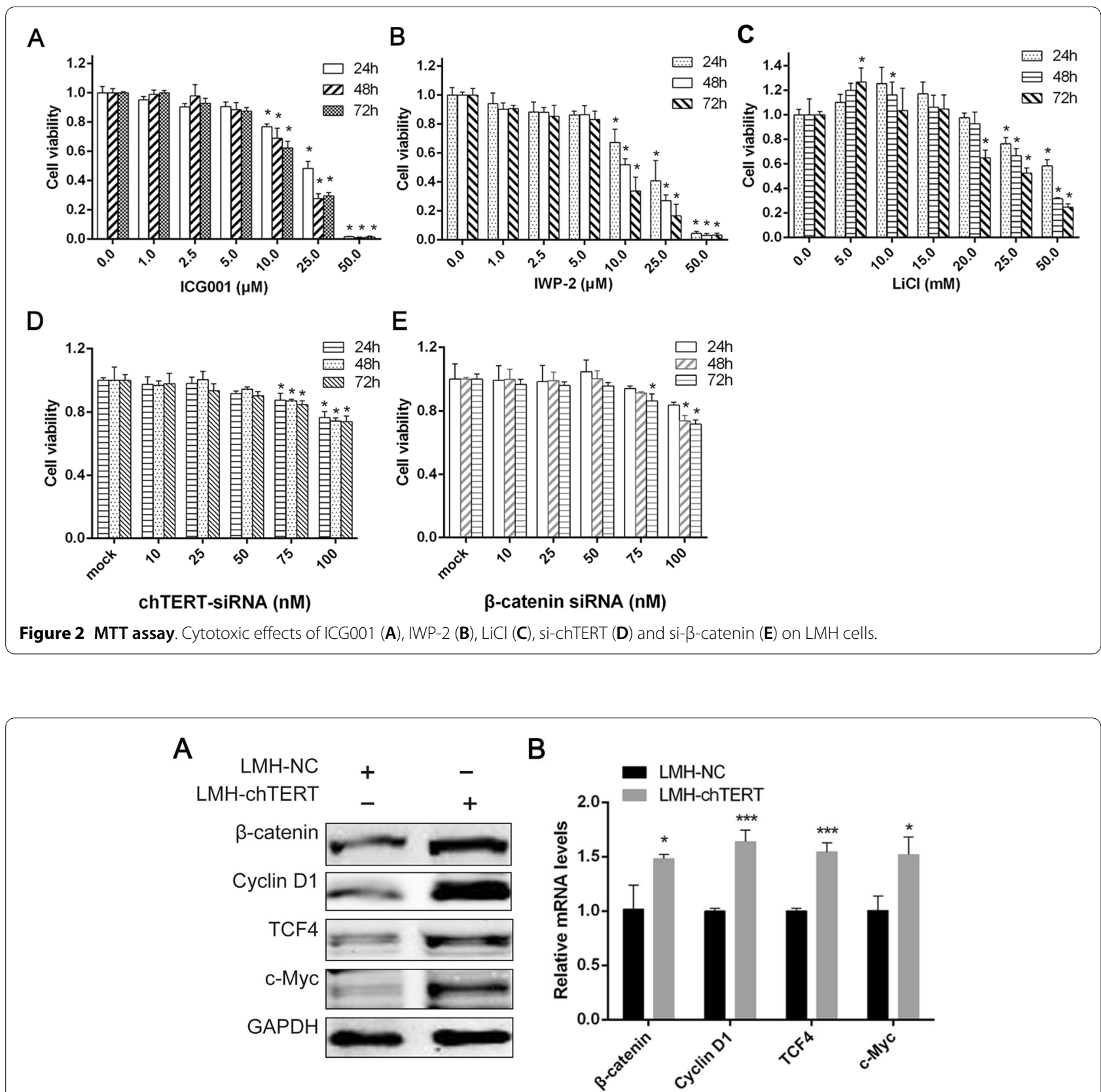

Figure 3 chTERT activated the Wnt/ $\boldsymbol{\beta}$-catenin signalling pathway. Western blotting $(\mathbf{A})$ and RT-PCR $(\mathbf{B})$ were used to measure the protein and mRNA expression levels of chTERT, respectively, in LMH-chTERT and LMH-NC cells.

and the tumour-related factor c-Myc (Figures 3A and B; $p<0.05)$. These results indicated that chTERT can activate the $\mathrm{Wnt} / \beta$-catenin signalling pathway and affect cell growth.
The $\beta$-catenin signalling pathway regulated chTERT expression and telomerase activity

To further verify the regulatory effect of chTERT on the Wnt/ $\beta$-catenin signalling pathway, si-chTERT was used to interfere with chTERT expression in LMHchTERT cells, and Wnt/ $\beta$-catenin signalling pathway activity was determined at $72 \mathrm{~h}$. In addition, to explore whether the $W n t / \beta$-catenin signalling pathway can 
regulate the expression of chTERT, LMH-chTERT cells were treated with inhibitors (ICG001 and IWP-2), an activator ( $\mathrm{LiCl})$ or si- $\beta$-catenin for $72 \mathrm{~h}$, and then, changes in chTERT expression and telomerase activity were measured by Western blotting, RT-PCR and TRAP. The results showed that when chTERT expression was inhibited by si-chTERT, $\beta$-catenin protein and mRNA expression was also inhibited, indicating that the activity of the $\mathrm{Wnt} / \beta$-catenin signalling pathway was reduced (Figures $4 \mathrm{~A}$ and $\mathrm{B} ; p<0.05$ ) and that the activity of telomerase was inhibited (Figure 4C; $p<0.01)$. Further experiments verified that chTERT overexpression could increase the activity of the Wnt/ $\beta$-catenin signalling pathway. Moreover, when cells were treated with ICG001, IWP- 2 and $\beta$-catenin siRNA, the activity of the $\mathrm{Wnt} / \beta$-catenin signalling pathway was inhibited, and the expression of chTERT was also significantly reduced (Figures 4A, D and $\mathrm{E} ; p<0.05)$. Similarly, telomerase activity in LMHchTERT cells was reduced after treatment with IWP-2 (Figure 4F; $p<0.01$ ). In contrast, the activity of the
Wnt $/ \beta$-catenin signalling pathway and the expression of chTERT were both increased after $\mathrm{LiCl}$ treatment (Figures $4 \mathrm{D}$ and $\mathrm{E} ; p<0.05$ ), and telomerase activity was also significantly increased (Figure 4F; $p<0.01$ ). These findings further suggested that the $\beta$-catenin signalling pathway and chTERT gene can mutually regulate each other and promote the activity/expression of the other.

\section{chTERT promoted the proliferation of LMH cells}

As the above results showed that chTERT increases the activity of the $\mathrm{Wnt} / \beta$-catenin signalling pathway and promotes the expression of Cyclin D1, we postulated that chTERT affects the cell cycle and cell proliferation. To verify this conjecture, the cell cycle was analysed in LMH-chTERT and LMH-NC cells by flow cytometry. The results showed that chTERT overexpression promoted the transition of LMH cells from G1 to S phase and G2 and increased the ratio of S phase cells to G2 cells (Figure 5A; $p<0.001$ ), indicating a reduction in the time required for cell replication, which could theoretically

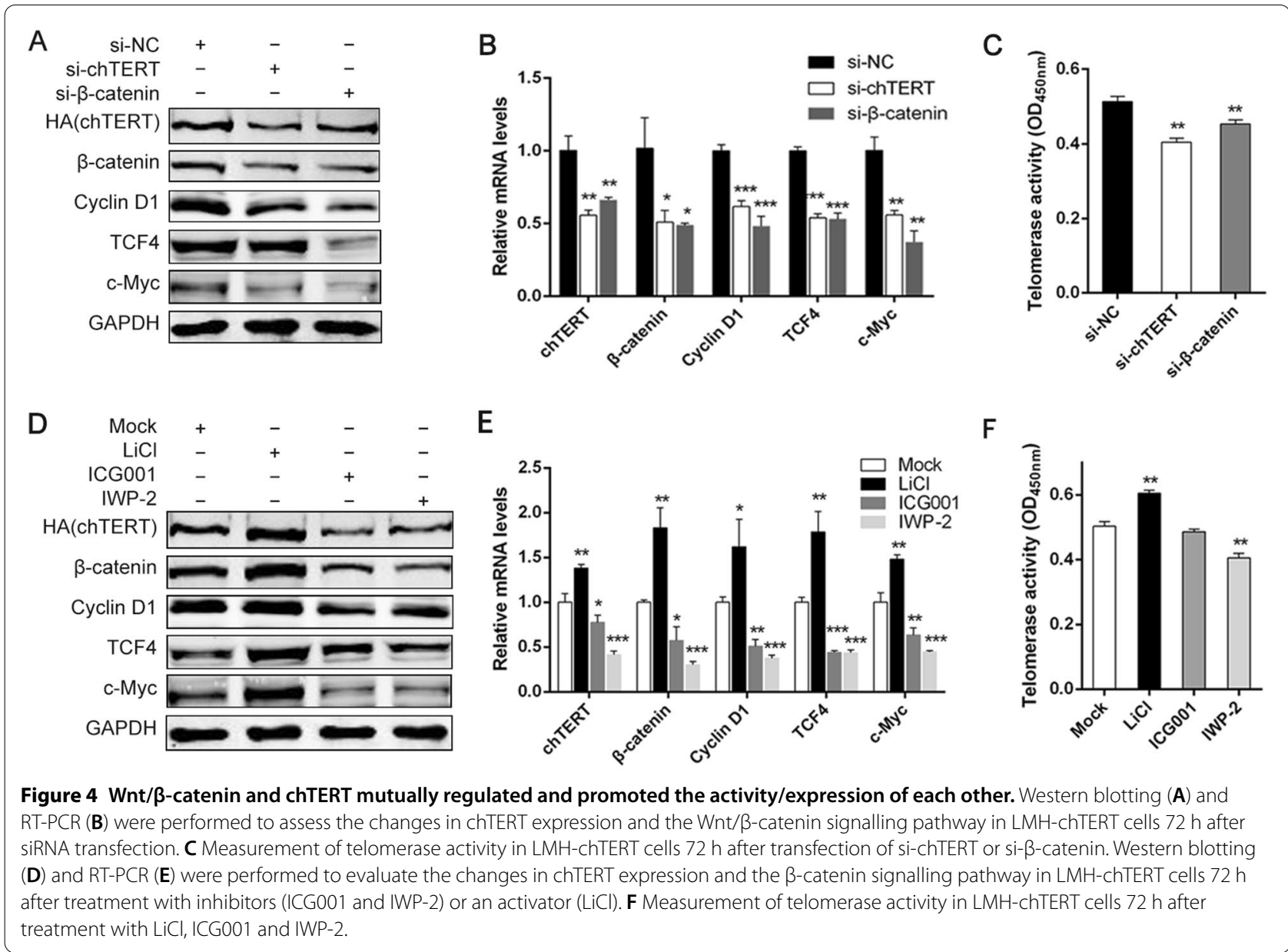




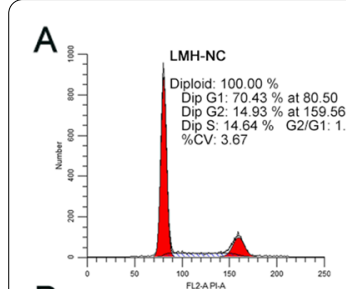

B
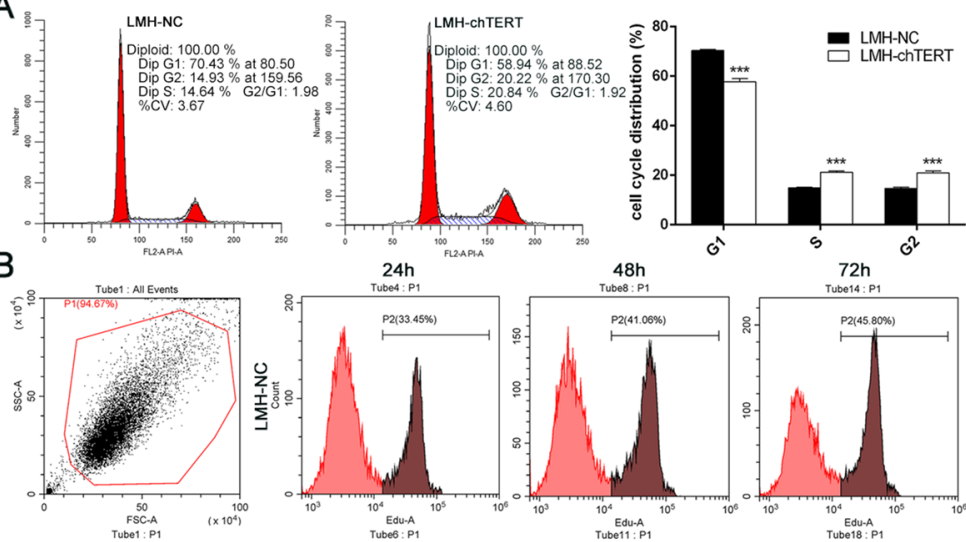

$\underset{T u \text { tues: } P 1}{48 h}$

$72 \mathrm{~h}$
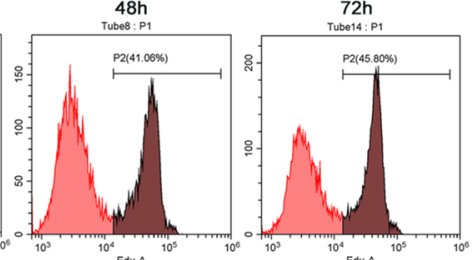

Edubes:-A
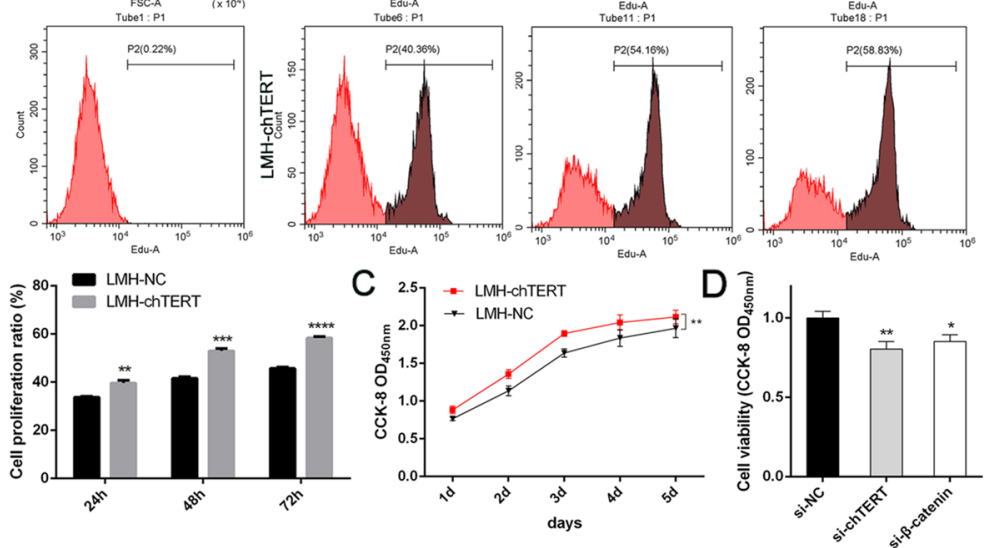

E
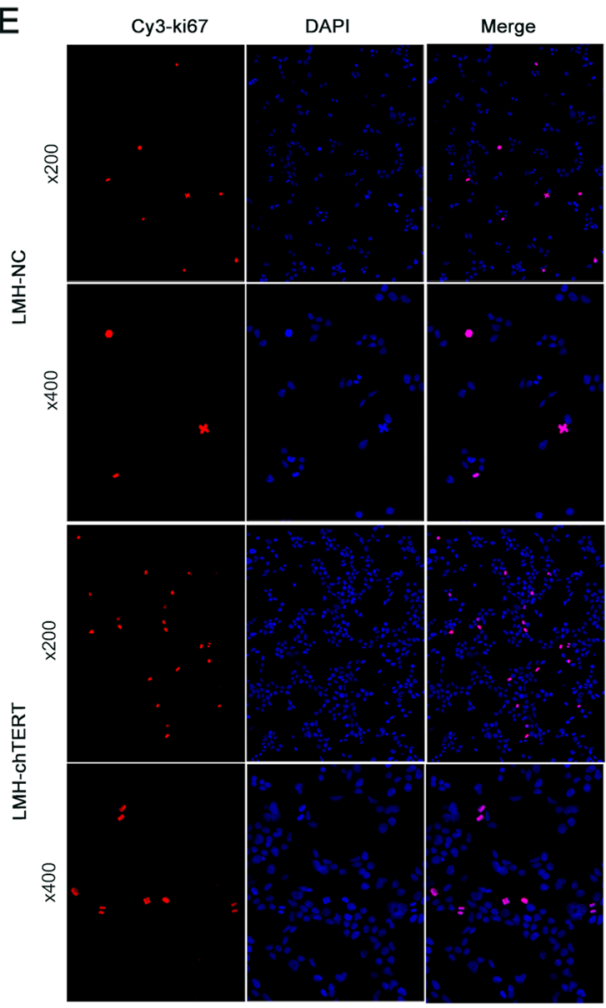

Figure 5 chTERT promoted the proliferation of LMH cells. A The cell cycle was analysed by flow cytometry. G1, the prophase of DNA synthesis. S phase, the DNA synthesis phase. G2, late phase of DNA synthesis. B Cell proliferation at 24, 48 and $72 \mathrm{~h}$ was analysed by flow cytometry. C The MTT assay was used to analyse the viability of LMH-chTERT and LMH-NC cells over 1-5 days. Growth curves were drawn after the values were read at a wavelength of $450 \mathrm{~nm}$. D The MTT assay was used to analyse the viability of LMH-chTERT cells $72 \mathrm{~h}$ after transfection with siRNA. $\mathbf{E}$ Immunofluorescence staining of Ki67, an antigen associated with proliferating cells. Ki67 is closely related to mitosis and is indispensable for cell proliferation.

promote cell proliferation. Subsequently, flow cytometry was used to analyse cell proliferation. The results showed that overexpression of chTERT significantly promoted the proliferation of LMH cells (Figure 5B; $p<0.01$ ). The same conclusion was obtained from growth curves for the two kinds of cells in MTT assays (Figures $5 \mathrm{C}$ and D; $p<0.05)$. Finally, Ki67 immunofluorescence staining verified that chTERT could promote the proliferation of LMH cells (Figure 5E).

\section{chTERT inhibited the apoptosis of LMH cells and induced a switch to autophagy}

Since regulation of the $\mathrm{Wnt} / \beta$-catenin signalling pathway by the chTERT gene is often associated with cell growth and development, the effect of chTERT on the apoptosis of LMH cells was explored. The results showed that the mRNA levels of genes that promote apoptosis, such as Caspase 3, Caspase 9 and BAX, were significantly lower in LMH-chTERT cells than in control cells, while the mRNA levels of genes that inhibit apoptosis, such as BCL-2 and BCL-X, were significantly higher than in control cells (Figure 6A; $p<0.05$ ). When the expression of the chTERT or $\beta$-catenin gene in LMH-chTERT cells was decreased by si-chTERT or si- $\beta$-catenin, similar results were obtained (Figure $6 \mathrm{~B} ; p<0.05$ ). The apoptosis of LMH cells was assessed in detail by flow cytometry, and the results showed that the proportions of early apoptotic, late apoptotic, and necrotic cells were lower in the LMH-chTERT group than in the LMH-NC group (Figure $6 \mathrm{C} ; p<0.01$ ). In addition, the late apoptosis of LMH cells was analysed by terminal-deoxynucleotidyl transferase-mediated nick end labelling (TUNEL) staining. The proportion of TUNEL-positive cells was lower in the chTERT overexpression group than in the control group (Figure 6D). To verify this finding more intuitively, TEM was performed, and the results showed fewer apoptotic bodies in LMH-chTERT cells than in LMH-NC cells (Figure 7). It is worth noting that there were more 


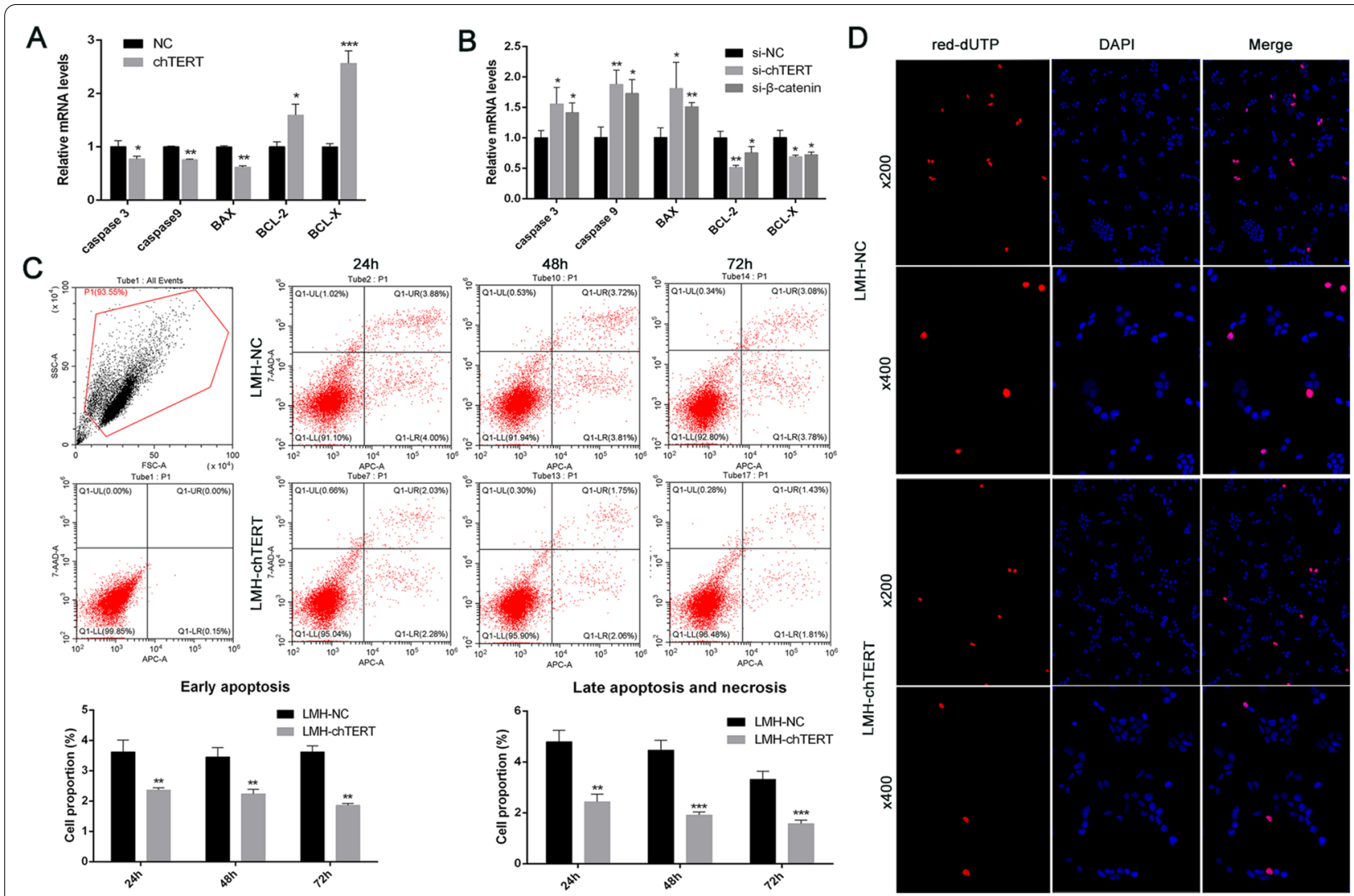

Figure 6 chTERT inhibited the apoptosis of LMH cells. A, B The mRNA levels of genes that promote apoptosis (Caspase 3, Caspase 9, and BAX) or inhibit apoptosis (BCL-2 and BCL-X) were measured by RT-PCR. C Flow cytometry analysis of early apoptotic, late apoptotic and necrotic LMH cells. APC-positive and 7-AAD-negative cells represent early apoptotic cells, and 7-AAD-positive cells represent late apoptotic or necrotic cells. D TUNEL staining was used to analyse late apoptotic LMH cells. In late apoptotic cells, chromosomal DNA breaks result in the production of a large number of sticky 3'-OH ends. Under the action of deoxyribonucleotide terminal transferase (TdT), deoxyribonucleotides, fluorescein, peroxide derivatives, alkaline phosphatase, or biotin are added to the 3'-end of the DNA, allowing apoptotic cells to be detected.

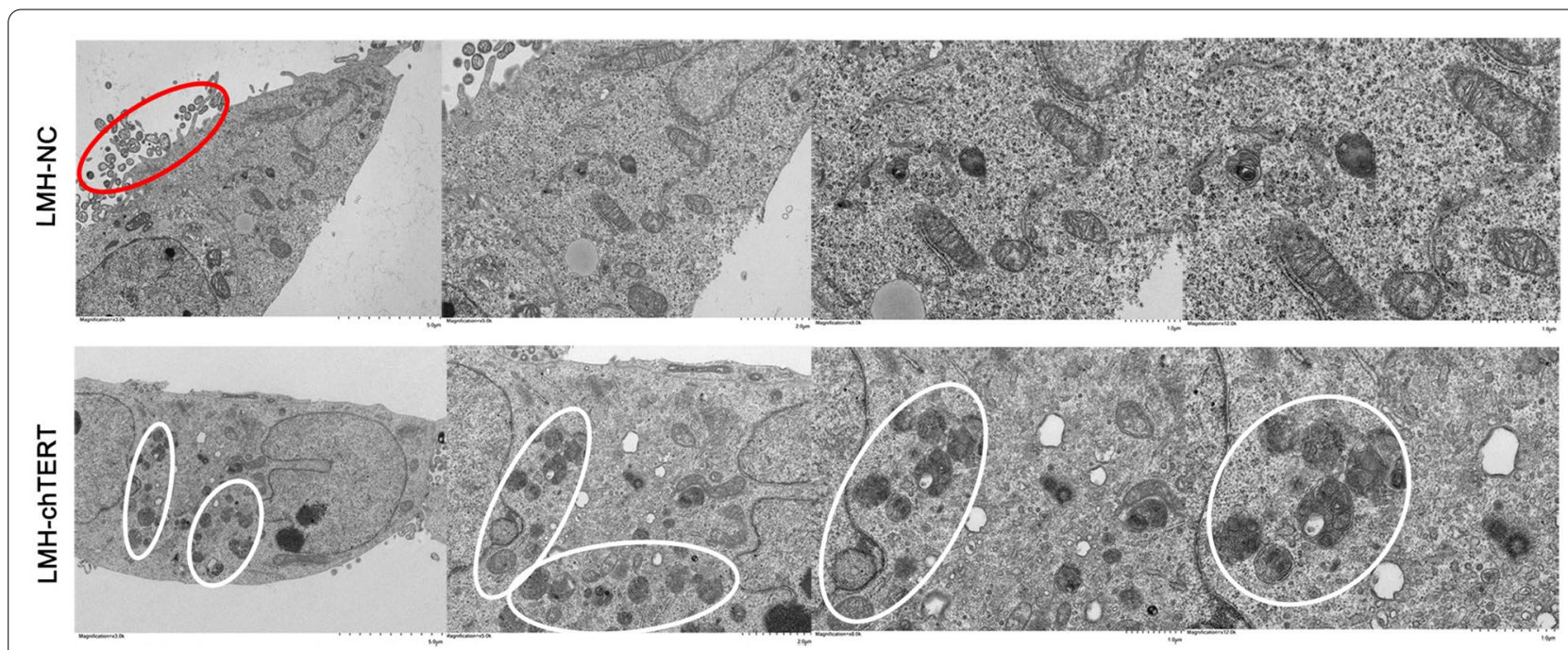

Figure 7 Transmission electron microscopy. chTERT inhibited the apoptosis of LMH cells and promoted the switch to autophagy. Apoptotic bodies are circled in red, and autophagosomes are circled in white. 
autophagosomes in LMH-chTERT cells than in control cells. In addition to indicating that the chTERT gene can inhibit the apoptosis of LMH cells, this finding suggested that overexpression of the chTERT gene promotes the autophagy of LMH cells. These data suggest that chTERT can reduce apoptosis by inducing a switch to autophagy.

\section{chTERT promoted the migration of LMH cells}

Our previous study found that chTERT is highly expressed in myeloid tumours caused by ALV-J, which may be related to tumour development and progression [24]. The effect of chTERT on LMH cell migration was analysed in vitro by the wound healing assay. The migration rate of LMH-chTERT cells was significantly higher than that of LMH-NC cells at 24 and $48 \mathrm{~h}$ (Figure $8 ; p<0.001$ ), indicating that chTERT gene expression enhances the migration ability of LMH cells and indirectly suggesting that chTERT can indeed promote the development and progression of tumours.

\section{chTERT promoted the replication of ALV-J in LMH cells}

Since the chTERT gene is highly abundant in myeloid tumours caused by ALV-J, we asked whether it affects ALV-J replication in LMH cells. To answer this question, we assessed the change in chTERT expression in LMH-chTERT and LMH-NC cell pellets before and after infection with ALV-J for $72 \mathrm{~h}$. The cell culture supernatant was collected every day, ALV p27 antigen levels were measured by ELISA, and a growth curve was drawn for ALV-J. The results showed that the expression level of ALV-J was significantly higher in LMH-chTERT cells than in control cells regardless of gp 85 mRNA or protein level (Figures 9A and B; $p<0.01$ ). Moreover, the content of ALV-J p27 antigen in the supernatant of LMH-chTERT cells was significantly higher than that in the supernatant of control cells (Figure 9C; $p<0.01$ ), which was consistent with the $\mathrm{TCID}_{50}$ values (Figure 9D; $p<0.05$ ). The above results indicated that chTERT can promote the replication of ALV-J in LMH cells. To explore whether ALV-J can affect the expression of chTERT, LMH-chTERT cells were infected with ALV-J at different MOIs, and an uninfected group was used as a control. The results showed that chTERT expression was significantly higher in cells infected with ALV-J at an MOI of 0.1 or 1.0 than in control cells (Figure 9E and F; $p<0.05$ ) and that telomerase activity was also increased in infected cells, indicating that ALV-J can promote the expression of chTERT. These data indicate that chTERT probably plays an important role in the pathogenesis of ALV-J infection.

\section{Discussion}

Telomerase reverse transcriptase is a key component of telomerase, which plays an important role in maintaining telomere stability and regulating cell growth and development. Telomerase reverse transcriptase has become an important target for the diagnosis and treatment of

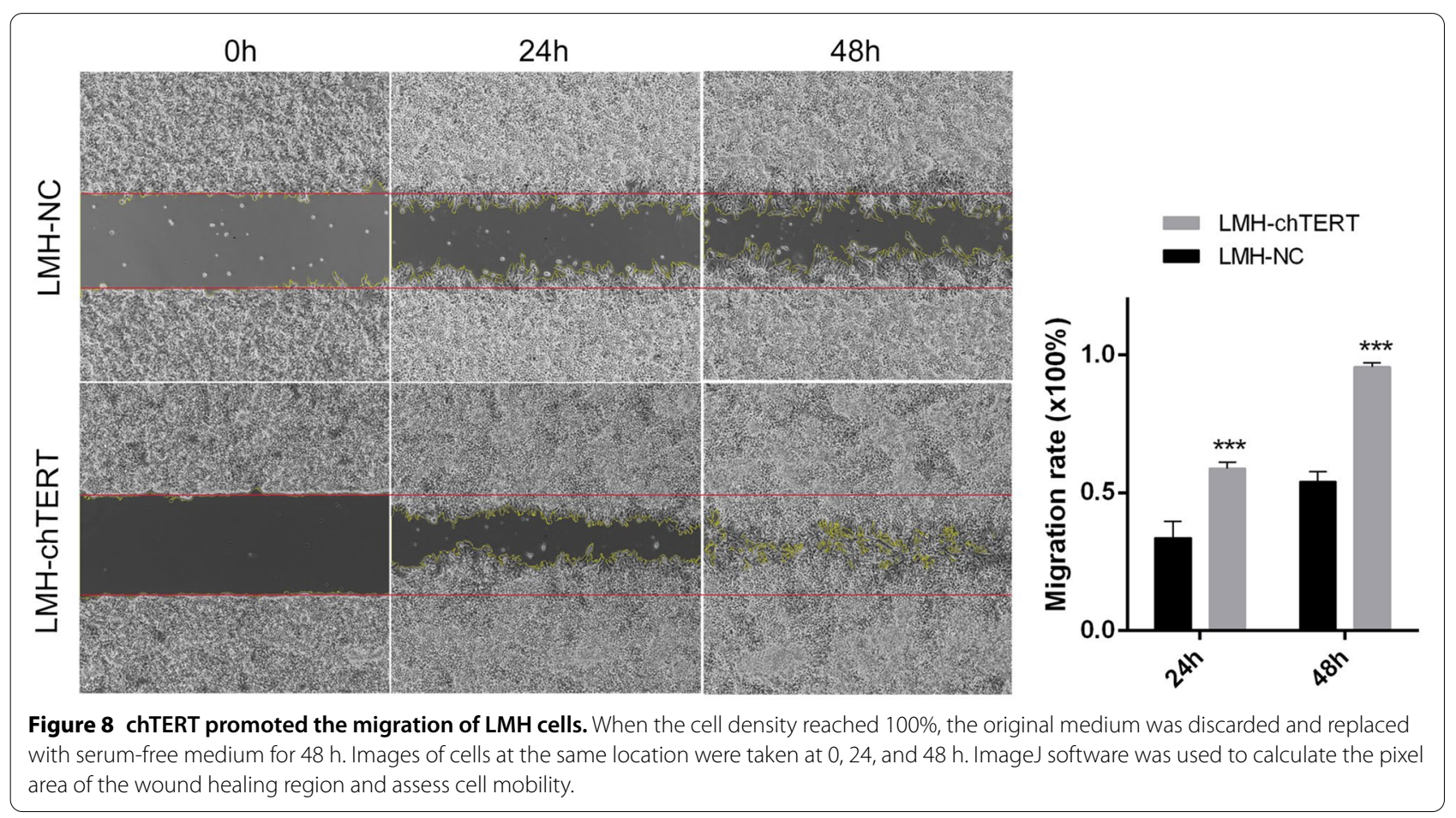


A

ALV-J

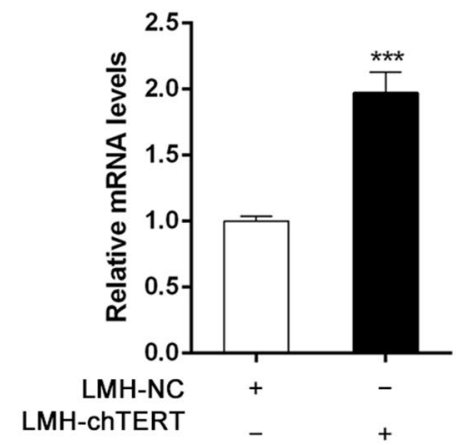

LMH-chTERT

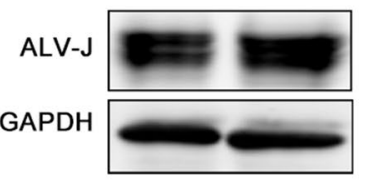

B

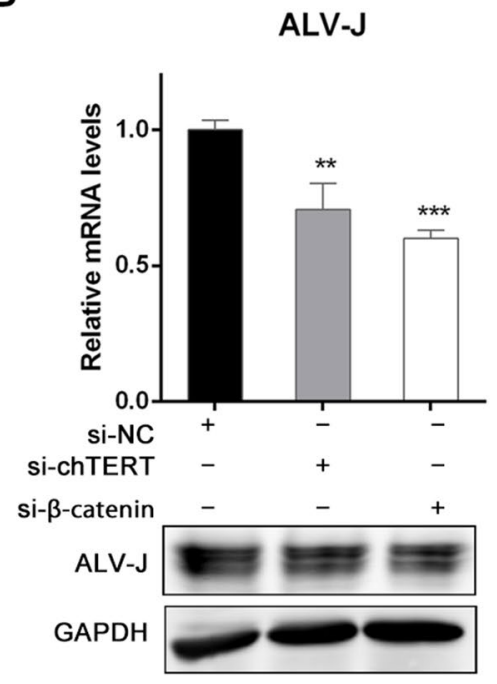

C

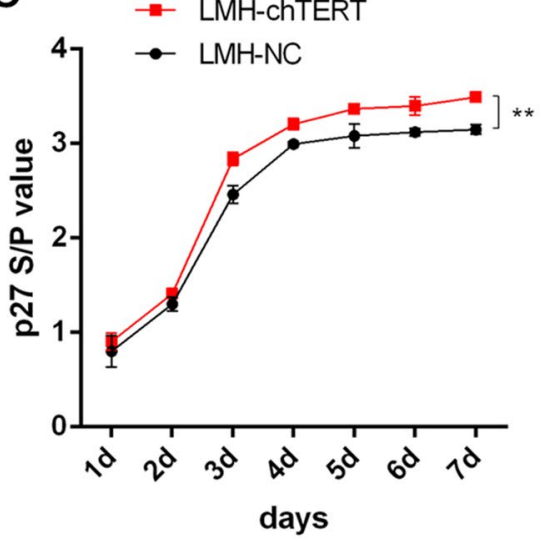

D

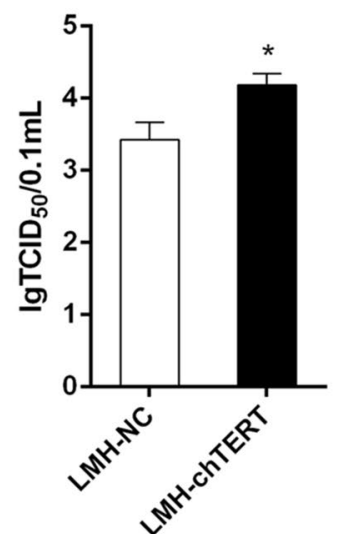

E

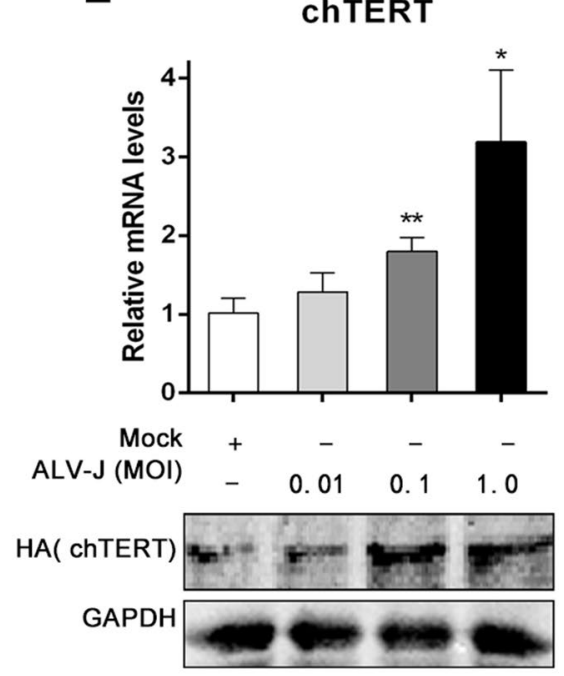

$\mathrm{F}$

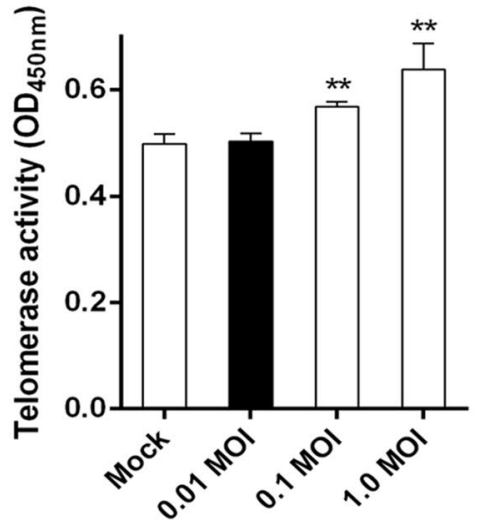

Figure 9 chTERT promoted the replication of ALV-J in LMH cells. A Seventy-two hours after LMH-chTERT and LMH-NC cells were infected with the same amount of ALV-J (CHN06), the level of ALV-J in the cell pellet was measured by RT-PCR and Western blotting. B LMH-chTERT cells were transfected with chTERT and $\beta$-catenin siRNAs and then inoculated with the same amount of ALV-J. After $72 \mathrm{~h}$ of incubation, the ALV-J level was measured by RT-PCR and Western blotting. The figure shows that after inhibiting chTERT gene expression or $\beta$-catenin signalling pathway activity, the replication of ALV-J was inhibited. C LMH-ChTERT and LMH-NC cells were infected with the same amount of ALV-J virus. After $2 \mathrm{~h}$ of incubation, the virus solution was discarded and replaced with new culture medium containing $1 \%$ FBS for 7 days. Then, the supernatant was collected every day to detect the p27 antigen. D The effect of chTERT on the virus titre of ALV-J. E LMH-chTERT cells were infected with ALV-J at an MOI of $0.01,0.1$ or 1.0. After $72 \mathrm{~h}$ of incubation, the expression of chTERT in the cell pellets of the infected and uninfected groups was measured by RT-PCR and Western blotting, and telomerase activity was also assessed (F).

human tumours [38, 39]. Activation of the hTERT gene is strictly regulated by a variety of signalling pathways in different human tumours, specifically the $\mathrm{Wnt} / \beta$-catenin, NF- $\mathrm{kB}$ and c-Myc signalling pathways $[10,13,28,40$, 41]. However, during ALV-J-induced tumorigenesis, the molecular mechanism by which the chTERT gene regulates the Wnt/ $\beta$-catenin signalling pathway and participates in cell growth and virus replication is still unknown. Therefore, exploring the interaction between the chTERT gene and the Wnt/B-catenin signalling pathway is of great significance to obtain an in-depth understanding of the role of chTERT in ALV-induced tumorigenicity.

In this study, the chTERT gene was amplified from muscle tissue of 4- to 7-day-old chicken embryos. Due to the large size of chTERT, the transfection efficiency of chTERT in chicken-derived cell lines is usually extremely low and not sufficient for research. Therefore, an immortal stable chTERT-overexpressing cell line 
was constructed by transfection with a lentiviral vector. Before a suitable cell line was selected, chTERT gene expression and telomerase activity in the commonly used chicken-derived cell lines DF-1 and LMH were measured. The results showed that DF-1 cells may not express the chTERT gene and are negative for telomerase, but LMH cells express the chTERT gene at a low level and are positive for telomerase (Figure 1B). Therefore, to conduct further comparative experiments, we infected these two cell lines with recombinant lentivirus and screened for DF-1 and LMH cells stably overexpressing the chTERT gene. However, the expression level of chTERT was significantly lower in DF-1 cells overexpressing chTERT than that in LMH-chTERT cells and decreased rapidly as the cells were passaged until chTERT was no longer expressed (data not shown). DF-1 cells are telomerase-negative immortal cells, not cancer cells, and their immortal proliferation does not depend on chTERT but rather on another mechanism, that is, alternative lengthening of telomeres [42]; this may be why the chTERT gene could not be stably expressed in DF-1 cells. As LMH cells are telomerase-positive cancer cells, the chTERT gene could be stably overexpressed; thus, stable chTERToverexpressing cells are similar to tumour cells infected with ALV. Therefore, LMH cells were used as the research platform in this study.

This study showed that chTERT can activate the Wnt/ $\beta$-catenin signalling pathway in LMH cells. Interestingly, after the Wnt $/ \beta$-catenin signalling pathway was activated by $\mathrm{LiCl}$, the mRNA and protein expression of chTERT and telomerase activity were significantly increased. These data demonstrated that the $\mathrm{Wnt} / \beta$-catenin signalling pathway can positively regulate chTERT expression. However, whereas the mRNA level of chTERT increased nearly 400-fold in LMH-chTERT cells, the increase in telomerase activity was not as great. First, the TERT mRNA expression level of LMH cells is relatively low, but these cells do have telomerase activity. However, after overexpression of TERT, the mRNA level increased; this is the same thing as having a higher ratio because the denominator is smaller. In this study, telomerase activity was analysed by telomere repeat sequence amplification, a method combining PCR with ELISA. That is, the final results were detected by ELISA after PCR amplification, which led to the change in telomerase activity not being as significant as that in chTERT mRNA expression level. This TRAP method cannot accurately quantify the original telomerase activity but better reflects the trend of change. On the other hand, the obtained results may also stem from a decreased efficiency in translating the foreign HA-labelled TERT gene. The detected protein level of HA-labelled TERT was not as high as expected, and thus, the difference was not as large as that in mRNA levels. This may also explain why the difference in telomerase activity was not as significant as that in the mRNA level. To further confirm that the $\mathrm{Wnt} / \beta$-catenin signalling pathway can positively regulate chTERT expression, LMH-chTERT cells were transfected with siRNA targeting chTERT. The results were s expected. When the expression of the chTERT gene was inhibited, telomerase activity was reduced, and the activity of the Wnt $/ \beta$ catenin signalling pathway was significantly decreased. In addition, after the activity of the $\beta$-catenin signalling pathway was inhibited by ICG001, IWP-2 and siRNA, the expression of chTERT was significantly reduced, and the activity of telomerase was decreased, further proving the above conclusion. Our results suggested that $\beta$-catenin mediates chTERT expression at both the mRNA and protein levels and influences telomerase activity. Moreover, there was a mutually positive regulatory relationship between chTERT and the $\beta$-catenin signalling pathway. This finding is consistent with the results of studies on TERT in a variety of human tumours and tumour cells $[10,31,43]$.

Many studies have shown that hTERT and $\beta$-catenin actively participate in cell growth and development [44, 45 ] and regulate the development of a variety of human malignancies [46, 47]. To explore whether chTERT and $\beta$-catenin play similar roles in LMH cells, we analysed the effect of chTERT on cell growth by CCK-8 assays, RT-PCR, flow cytometry, immunofluorescence staining and TEM. We found that chTERT reduced the number of LMH cells in the G1 phase of the cell cycle and increase the number of cells in S phase and G2; thus, it arrested the cell cycle at $\mathrm{S}$ phase, thereby shortening the cell cycle and promoting the proliferation of LMH cells. Moreover, chTERT inhibited the apoptosis of LMH by downregulating the mRNA expression of Caspase 3, Caspase 9 and BAX, which are associated with promoting apoptosis [48]; by upregulating the mRNA expression of BCL-2 and BCL-X, which are associated with inhibiting apoptosis [49]; and by promoting autophagy to inhibit apoptosis.

ALV-J can induce apoptosis and inhibit autophagy to slow cell growth [50-52]. In this study, the overexpression of chTERT in LMH cells inhibited the apoptosis of ALV-J-infected cells and promoted autophagy, ultimately promoting cell proliferation. Therefore, cells overexpressing chTERT can somewhat offset apoptosis induced by ALV-J infection, which indicates that chTERT can improve the viability of cells infected with ALV-J. Thus, compared with control cells, cells overexpressing chTERT significantly promoted the replication of ALV$\mathrm{J}$. In addition, this study showed that overexpression of chTERT can enhance the migration ability of LMH cells, which confirms that the migratory activity of tumour cells is better than that of normal cells [53]. Finally, we 


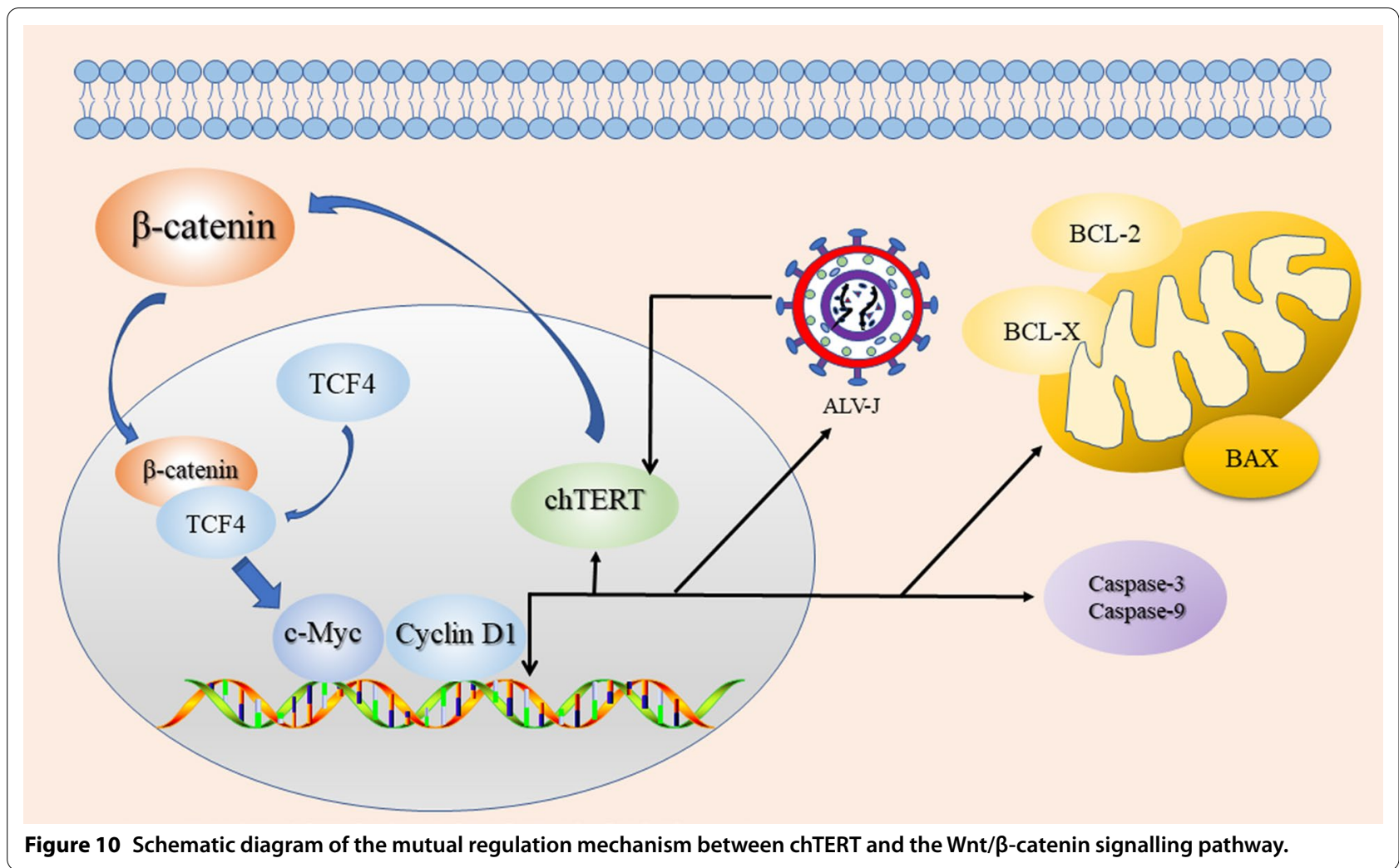

analysed the effect of ALV-J on the expression of chTERT and found that ALV-J significantly increased chTERT mRNA and protein expression. This finding is consistent with previous research showing that chTERT is a common integration site of ALV-J [24].

During the replication process of ALV, the sites of its own genome insertion and integration into the host genes are generally random, which is why tumour formation after infection with chronic transformed ALV is relatively rare. However, our previous study showed that in tumours caused by ALV-J, the virus insertion and integration sites were concentrated in the exon regions of the MYC, TERT and Z1C1 genes or upstream of the transcription sites, preliminarily suggesting that the integration of ALV-J in the host genome is actually weakly selective [24]. In this study, we found that chTERT overexpression promoted the replication of ALV-J, mainly because chTERT promotes virus replication by regulating the Wnt/ $\beta$-catenin signalling pathway to affect cell growth and provide a better environment for ALV-J replication. On the other hand, when chTERT was overexpressed, the probability of ALV-J insertion and integration near chTERT actually increased. Previous studies have shown that the integration of ALV-J upstream of the chTERT gene can lead to an increase in gene transcription [24]. Therefore, if the probability of ALV-J insertion and integration near chTERT increases, the expression of chTERT will also be upregulated. If the MOI of ALV-J is increased at the same time, then this probability will be further increased; thus, the replication of ALV-J will also affect the expression of chTERT. Increased expression of chTERT in turn promotes cell proliferation and inhibits cell apoptosis, thereby providing a better environment for ALV-J replication. However, stronger evidence is needed to ascertain whether chTERT can directly affect the replication ability of the virus itself.

In summary, chTERT and the $\mathrm{Wnt} / \beta$-catenin signalling pathway can positively regulate each other in LMH cells, inhibiting apoptosis and promoting autophagy by downregulating the mRNA expression of Caspase 3, Caspase 9 and BAX and upregulating BCL-2 and BCL-X expression. In addition, chTERT can shorten the cell cycle to enhance proliferation and ultimately promote cell migration and the replication of ALV-J in LMH cells (Figure 10). Our findings help reveal the role of chTERT in ALV-J-induced oncogenesis.

\section{Abbreviations}

chTERT: chicken telomerase reverse transcriptase; hTERT: human telomerase reverse transcriptase; ALVs: avian leukosis viruses; ALV-J: avian leukosis virus subgroup J; LMH-chTERT: LMH cells stably overexpressing the chTERT gene; LMH-NC: negative control cells for LMH-chTERT; siRNA: small interfering RNA: TRAP: telomeric repeat amplification protocol; TEM: transmission electron 
microscopy; ELISA: enzyme-linked immunosorbent assay; MOI: multiplicity of infection; TUNEL: terminal-deoxynucleotidyl transferase-mediated nick end labelling; $\mathrm{TCID}_{50}$ : 50\% Tissue culture infection dose; AA: amino acid.

\section{Supplementary Information}

The online version contains supplementary material available at https://doi. org/10.1186/s13567-021-00979-x.

\section{Additional file 1: Agarose gel electrophoresis of chTERT gene cloning ( $A, B$ and $C$ ) and identification of the PLV-chTERT-HA plasmid by restriction enzyme digest $(D)$.}

\section{Acknowledgements}

We would like to thank Professor Ming Liao (South China Agriculture University) for providing the $293 \mathrm{~T}$ cells and LMH cells, Avian Disease and Oncology Laboratory (USA) for providing the mouse monoclonal antibodies (G2.3) against the gp85 protein of ALV-J, and Springer Nature Author Services for editing the manuscript for proper English language, grammar, and spelling.

\section{Authors' contributions}

YX and WC conceived and designed the study. YX, YY, QL, JZ, JL and CL performed the experiments. YX, YY and WC analysed the data. YX and WC wrote the paper. JC, YL, XC and WC contributed to the critical revision of the manuscript. All authors read and approved the final manuscript.

\section{Funding}

This study was supported by the Key-Area Research and Development Program of Guangdong Province (2020B020222001), the National Key R\&D Project (2016YFD0501606), the Poultry Industry Technology System of Guangdong (2020KJ128), and the China Agriculture Research System of MOF and MARA (CARS-41).

\section{Availability of data and materials}

The data on which the conclusions of the manuscript rely are presented in the main paper.

\section{Declarations}

\section{Competing interests}

The authors declare that they have no competing interests.

\section{Author details}

${ }^{1}$ College of Veterinary Medicine, South China Agricultural University, Guangzhou 510642, China. ${ }^{2}$ Key Laboratory of Zoonosis Prevention and Control of Guangdong Province, South China Agricultural University, Guangzhou 510642, China. ${ }^{3}$ Guangdong Laboratory for Lingnan Modern Agriculture, South China Agricultural University, Guangzhou 510642, China. ${ }^{4}$ National and Regional Joint Engineering Laboratory for Medicament of Zoonosis Prevention and Control, South China Agricultural University, Guangzhou 510642, China. ${ }^{5}$ Key Laboratory of Veterinary Vaccine Innovation of the Ministry of Agriculture, Guangzhou 510642, China.

Received: 8 May 2021 Accepted: 10 July 2021

Published online: 19 August 2021

\section{References}

1. Stone RC, Aviv A, Paus R (2021) Telomere dynamics and telomerase in the biology of hair follicles and their stem cells as a model for aging research. J Invest Dermatol 141:1031-1040. https://doi.org/10.1016/j.jid.2020.12. 006

2. Delany ME, Krupkin AB, Miller MM (2000) Organization of telomere sequences in birds: evidence for arrays of extreme length and for in vivo shortening. Cytogenet Cell Genet 90:139-145. https://doi.org/10.1159/ 000015649
3. Zhang Z, Wang J, Li J, Xu S (2011) Telomerase-mediated apoptosis of chicken lymphoblastoid tumor cell line by lanthanum chloride. Biol Trace Elem Res 144:657-667. https://doi.org/10.1007/s12011-011-9027-8

4. Casadio V, Bravaccini S (2021) Telomerase activity analysis in urine sediment for bladder cancer. Methods Mol Biol 2292:133-141. https://doi. org/10.1007/978-1-0716-1354-2_12

5. Bradfield A, Button L, Drury J, Green DC, Hill CJ, Hapangama DK (2020) Investigating the role of telomere and telomerase associated genes and proteins in endometrial cancer. Methods Protoc 3:63. https://doi.org/10 3390/mps3030063

6. Roggisch J, Ecke T, Koch S (2020) Molecular identification of telomerase reverse transcriptase (TERT) promotor mutations in primary and recurrent tumors of invasive and noninvasive urothelial bladder cancer. Urol Oncol 38:77.e17-77.e25. https://doi.org/10.1016/j.urolonc.2019.08.007

7. Perera ON, Sobinoff AP, Teber ET, Harman A, Maritz MF, Yang SF, Pickett HA, Cesare AJ, Arthur JW, MacKenzie KL, Bryan TM (2019) Telomerase promotes formation of a telomere protective complex in cancer cells. Sci Adv 5:eaav4409. https://doi.org/10.1126/sciadv.aav4409

8. Kheimar A, Trimpert J, Groenke N, Kaufer BB (2019) Overexpression of cellular telomerase RNA enhances virus-induced cancer formation. Oncogene 38:1778-1786. https://doi.org/10.1038/s41388-018-0544-1

9. Maggisano V, Celano M, Lepore SM, Sponziello M, Rosignolo F, Pecce V, Verrienti A, Baldan F, Mio C, Allegri L, Maranghi M, Falcone R, Damante G, Russo D, Bulotta S (2019) Human telomerase reverse transcriptase in papillary thyroid cancer: gene expression, effects of silencing and regulation by BET inhibitors in thyroid cancer cells. Endocrine 63:545-553. https:// doi.org/10.1007/s12020-018-01836-2

10. Liu J, Wen Y, Luo W, Liu Y, Sha X (2021) Human amniotic epithelial cells promote the proliferation of human corneal endothelial cells by regulating telomerase activity via the Wnt/beta-catenin pathway. Curr Eye Res 46:159-167. https://doi.org/10.1080/02713683.2020.1792508

11. Yu D, Shang Y, Yuan J, Ding S, Luo S, Hao L (2016) Wnt/beta-catenin signaling exacerbates keloid cell proliferation by regulating telomerase. Cell Physiol Biochem 39:2001-2013. https://doi.org/10.1159/000447896

12. Jaitner S, Reiche JA, Schaffauer AJ, Hiendlmeyer E, Herbst H, Brabletz T, Kirchner T, Jung A (2012) Human telomerase reverse transcriptase (hTERT) is a target gene of beta-catenin in human colorectal tumors. Cell Cycle 11:3331-3338. https://doi.org/10.4161/cc.21790

13. Zuo QP, Liu SK, Li ZJ, Li B, Zhou YL, Guo R, Huang LH (2011) NF-kappaB p65 modulates the telomerase reverse transcriptase in the HepG(2) hepatoma cell line. Eur J Pharmacol 672:113-120. https://doi.org/10. 1016/j.ejphar.2011.09.187

14. Wu Y, Bian C, Zhen C, Liu L, Lin Z, Nisar MF, Wang M, Bartsch JW, Huang E, Ji P, Yang L, Yu Y, Yang J, Jiang X, Zhong JL (2017) Telomerase reverse transcriptase mediates EMT through NF-kappaB signaling in tongue squamous cell carcinoma. Oncotarget 8:85492-85503. https://doi.org/10. 18632/oncotarget.20888

15. Baena-Del Valle JA, Zheng Q, Esopi DM, Rubenstein M, Hubbard GK, Moncaliano MC, Hruszkewycz A, Vaghasia A, Yegnasubramanian S, Wheelan SJ, Meeker AK, Heaphy CM, Graham MK, De Marzo AM (2018) MYC drives overexpression of telomerase RNA (hTR/TERC) in prostate cancer. J Pathol 244:11-24. https://doi.org/10.1002/path.4980

16. Koh CM, Khattar E, Leow SC, Liu CY, Muller J, Ang WX, Li Y, Franzoso G, Li S, Guccione E, Tergaonkar V (2015) Telomerase regulates MYC-driven oncogenesis independent of its reverse transcriptase activity. J Clin Invest 125:2109-2122. https://doi.org/10.1172/JCI79134

17. Ren C, Yu M, Zhang Y, Fan M, Chang F, Xing L, Liu Y, Wang Y, Qi X, Liu C, Zhang Y, Cui H, Li K, Gao L, Pan Q, Wang X, Gao Y (2018) Avian leukosis virus subgroup J promotes cell proliferation and cell cycle progression through miR-221 by targeting CDKN1B. Virology 519:121-130. https://doi. org/10.1016/j.virol.2018.04.008

18. Dai Z, Ji J, Yan Y, Lin W, Li H, Chen F, Liu Y, Chen W, Bi Y, Xie Q (2015) Role of gga-miR-221 and gga-miR-222 during tumour formation in chickens infected by subgroup J avian leukosis virus. Viruses 7:6538-6551. https:// doi.org/10.3390/v7122956

19. Smith LP, Petheridge $L$, Nair $V$, Wood A, Welchman D (2018) Avian leukosis virus subgroup J-associated myelocytoma in a hobby chicken. Vet Rec 182:23. https://doi.org/10.1136/vr.104626

20. Liu P, Li L, Jiang Z, Yu Y, Chen X, Xiang Y, Chen J, Li Y, Cao W (2021) Molecular characteristics of subgroup $J$ avian leukosis virus isolated from yellow 
breeder chickens in Guangdong, China, during 2016-2019. Infect Genet Evol 89:104721. https://doi.org/10.1016/j.meegid.2021.104721

21. Cui N, Cui X, Huang Q, Yang S, Su S, Xu C, Li J, Li W, Li C (2020) Isolation and Identification of subgroup J avian leukosis virus inducing multiple systemic tumors in parental meat-type chickens. Front Vet Sci 7:614854. https://doi.org/10.3389/fvets.2020.614854

22. Li H, Tan M, Zhang F, Ji H, Zeng Y, Yang Q, Tan J, Huang J, Su Q, Huang Y, Kang Z (2021) Diversity of avian leukosis virus subgroup J in local chickens, Jiangxi, China. Sci Rep 11:4797. https://doi.org/10.1038/ s41598-021-84189-7

23. Yang F, Xian RR, LiY, Polony TS, Beemon KL (2007) Telomerase reverse transcriptase expression elevated by avian leukosis virus integration in $\mathrm{B}$ cell lymphomas. Proc Natl Acad Sci U S A 104:18952-18957. https://doi. org/10.1073/pnas.0709173104

24. Li Y, Liu X, Yang Z, Xu C, Liu D, Qin J, Dai M, Hao J, Feng M, Huang X, Tan L, Cao W, Liao M (2014) The MYC, TERT, and ZIC1 genes are common targets of viral integration and transcriptional deregulation in avian leukosis virus subgroup J-induced myeloid leukosis. J Virol 88:3182-3191. https://doi. org/10.1128/JVI.02995-13

25. Kar S, Jasuja H, Katti DR, Katti KS (2020) Wnt/beta-catenin signaling pathway regulates osteogenesis for breast cancer bone metastasis: experiments in an in vitro nanoclay scaffold cancer testbed. ACS Biomater Sci Eng 6:2600-2611. https://doi.org/10.1021/acsbiomaterials.9b00923

26. Li X, Xiang Y, Li F, Yin C, Li B, Ke X (2019) WNT/beta-catenin signaling pathway regulating $T$ cell-inflammation in the tumor microenvironment. Front Immunol 10:2293. https://doi.org/10.3389/fimmu.2019.02293

27. Tong X, Zhuang Z, Wang X, Yang X, Bai L, Su L, Wei P, Su X (2021) ACBP suppresses the proliferation, migration, and invasion of colorectal cancer via targeting Wnt/beta-catenin signaling pathway. Biomed Pharmacother 137:111209. https://doi.org/10.1016/j.biopha.2020.111209

28. Yang F, Guo Z, He C, Qing L, Wang H, Wu J, Lu X (2021) Cancer-associated fibroblasts promote cell proliferation and invasion via paracrine Wnt/ IL 1 beta signaling pathway in human bladder cancer. Neoplasma 68:79-86. https://doi.org/10.4149/neo_2020_200202N101

29. He X, Meng F, Yu ZJ, Zhu XJ, Qin LY, Wu XR, Liu ZL, Li Y, Zheng YF (2021) PLCD1 suppressed cellular proliferation, invasion, and migration via inhibition of Wnt/beta-catenin signaling pathway in esophageal squamous cell carcinoma. Dig Dis Sci 66:442-451. https://doi.org/10.1007/ s10620-020-06218-1

30. Dong Q, Jie Y, Ma J, Li C, Xin T, Yang D (2021) Wnt/beta-catenin signaling pathway promotes renal ischemia-reperfusion injury through inducing oxidative stress and inflammation response. J Recept Signal Transduct Res 41:15-18. https://doi.org/10.1080/10799893.2020.1783555

31. Chen S, Yang L, Dong H, Guo H (2019) Human telomerase reverse transcriptase recruits the beta-catenin/TCF-4 complex to transactivate chemokine (C-C motif) ligand 2 expression in colorectal cancer. Biomed Pharmacother 112:108700. https://doi.org/10.1016/j.biopha.2019.108700

32. Listerman I, Gazzaniga FS, Blackburn EH (2014) An investigation of the effects of the core protein telomerase reverse transcriptase on Wnt signaling in breast cancer cells. Mol Cell Biol 34:280-289. https://doi.org/ 10.1128/MCB.00844-13

33. Zhang Y, Toh L, Lau P, Wang X (2012) Human telomerase reverse transcriptase (hTERT) is a novel target of the Wnt/beta-catenin pathway in human cancer. J Biol Chem 287:32494-32511. https://doi.org/10.1074/ jbc.M112.368282

34. Wang W, Zhang T, Wu C, Wang S, Wang Y, Li H, Wang N (2017) Immortalization of chicken preadipocytes by retroviral transduction of chicken TERT and TR. PLoS One 12:e0177348. https://doi.org/10.1371/journal. pone. 0177348

35. Ding L, Jiang Z, Wu J, Li D, Wang H, Lu W, Zeng Q, Xu G (2019) betacatenin signalling inhibits cartilage endplate chondrocyte homeostasis in vitro. Mol Med Rep 20:567-572. https://doi.org/10.3892/mmr.2019.10301

36. Hiyama A, Sakai D, Risbud MV, Tanaka M, Arai F, Abe K, Mochida J (2010) Enhancement of intervertebral disc cell senescence by WNT/betacatenin signaling-induced matrix metalloproteinase expression. Arthritis Rheum 62:3036-3047. https://doi.org/10.1002/art.27599

37. Kawasaki K, Kuboki S, Furukawa K, Takayashiki T, Takano S, Ohtsuka M (2021) LGR5 induces beta-catenin activation and augments tumour progression by activating STAT3 in human intrahepatic cholangiocarcinoma. Liver Int 41:865-881. https://doi.org/10.1111/liv.14747
38. Pestana A, Vinagre J, Sobrinho-Simoes M, Soares P (2017) TERT biology and function in cancer: beyond immortalisation. J Mol Endocrinol 58:R129-R146. https://doi.org/10.1530/JME-16-0195

39. Relitti N, Saraswati AP, Federico S, Khan T, Brindisi M, Zisterer D, Brogi S, Gemma S, Butini S, Campiani G (2020) Telomerase-based cancer therapeutics: a review on their clinical trials. Curr Top Med Chem 20:433-457. https://doi.org/10.2174/1568026620666200102104930

40. Shen Y, Xi F, Li H, Luo Y, Chen C, Wang L (2018) Telomerase reverse transcriptase suppression inhibits cell proliferation and promotes cell apoptosis in hepatocellular cancer. IUBMB Life 70:642-648. https://doi. org/10.1002/iub.1758

41. Long C, Xu QB, Ding L, Yang L, Ji W, Gao F, Ji Y (2021) Triptolide inhibits human telomerase reverse transcriptase by downregulating translation factors SP1 and c-Myc in Epstein-Barr virus-positive B lymphocytes. Oncol Lett 21:280. https://doi.org/10.3892/ol.2021.12541

42. O'Hare TH, Delany ME (2011) Molecular and cellular evidence for the alternative lengthening of telomeres (ALT) mechanism in chicken. Cytogenet Genome Res 135:65-78. https://doi.org/10.1159/000330125

43. Fathi E, Valipour B, Sanaat Z, Nozad Charoudeh H, Farahzadi R (2020) Interleukin-6,-8, and TGF-beta secreted from mesenchymal stem cells show functional role in reduction of telomerase activity of leukemia cell via Wnt5a/beta-catenin and P53 pathways. Adv Pharm Bull 10:307-314. https://doi.org/10.34172/apb.2020.037

44. Xu C, Xie N, Su Y, Sun Z, Liang Y, Zhang N, Liu D, Jia S, Xing X, Han L, Li G, Tong T, Chen J (2020) HnRNP F/H associate with hTERC and telomerase holoenzyme to modulate telomerase function and promote cell proliferation. Cell Death Differ 27:1998-2013. https://doi.org/10.1038/ s41418-019-0483-6

45. Du J, Liu H, Mao X, Qin Y, Fan C (2021) ATF4 promotes lung cancer cell proliferation and invasion partially through regulating Wnt/beta-catenin signaling. Int J Med Sci 18:1442-1448. https://doi.org/10.7150/ijms.43167

46. Xie W, Liu N, Wang X, Wei L, Xie W, Sheng X (2021) Wilms'tumor 1-associated protein contributes to chemo-resistance to cisplatin through the Wnt/beta-catenin pathway in endometrial cancer. Front Oncol 11:598344. https://doi.org/10.3389/fonc.2021.598344

47. Salimi-Jeda A, Badrzadeh F, Esghaei M, Abdoli A (2021) The role of telomerase and viruses interaction in cancer development, and telomerase-dependent therapeutic approaches. Cancer Treat Res Commun 27:100323. https://doi.org/10.1016/j.ctarc.2021.100323

48. Xu Y, Li Z, Zhang S, Zhang H, Teng X (2020) miR-187-5p/apaf-1 axis was involved in oxidative stress-mediated apoptosis caused by ammonia via mitochondrial pathway in chicken livers. Toxicol Appl Pharmacol 388:114869. https://doi.org/10.1016/j.taap.2019.114869

49. Zhang K, Zhu Y, Wang X, Zhao X, Li S, Teng X (2017) Excess manganeseinduced apoptosis in chicken cerebrums and embryonic neurocytes. Biol Trace Elem Res 180:297-305. https://doi.org/10.1007/s12011-017-0992-4

50. Liao Z, Zhang X, Song C, Lin W, Cheng Y, Xie Z, Chen S, Nie Y, Li A, Zhang $\mathrm{H}, \mathrm{Li}$ H, Li H, Xie Q (2020) ALV-J inhibits autophagy through the GADD45beta/MEKK4/P38MAPK signaling pathway and mediates apoptosis following autophagy. Cell Death Dis 11:684. https://doi.org/10.1038/ s41419-020-02841-y

51. Ren C, Xie R, Yao Y, Yu M, Chang F, Xing L, Zhang Y, Liu Y, Wang S, Farooque M, Wang Y, Qi X, Liu C, Zhang Y, Cui H, Li K, Gao L, Pan Q, Nair V, Wang X, Gao Y (2019) MiR-125b suppression inhibits apoptosis and negatively regulates Sema4D in avian leukosis virus-transformed cells. Viruses 11:728. https://doi.org/10.3390/v11080728

52. Liu D, Dai M, Zhang X, Cao W, Liao M (2016) Subgroup J avian leukosis virus infection of chicken dendritic cells induces apoptosis via the aberrant expression of microRNAs. Sci Rep 6:20188. https://doi.org/10.1038/ srep20188

53. Sanyal S, Mondal P, Sen S, Sengupta Bandyopadhyay S, Das C (2020) SUMO E3 ligase CBX4 regulates hTERT-mediated transcription of $\mathrm{CDH} 1$ and promotes breast cancer cell migration and invasion. Biochem J 477:3803-3818. https://doi.org/10.1042/BCJ20200359

54. Jin K, Chen H, Zuo Q, Huang C, Zhao R, Yu X, Wang Y, Zhang Y, Chang Z, Li B (2018) CREPT and p15RS regulate cell proliferation and cycling in chicken DF-1 cells through the Wnt/beta-catenin pathway. J Cell Biochem 119:1083-1092. https://doi.org/10.1002/jcb.26277

55. Swanberg SE, Payne WS, Hunt HD, Dodgson JB, Delany ME (2004) Telomerase activity and differential expression of telomerase genes and c-myc 
in chicken cells in vitro. Dev Dyn 231:14-21. https://doi.org/10.1002/dvdy. 20149

56. Chen M, Li X, Fan R, Cao C, Yao H, Xu S (2017) Selenium antagonizes cadmium-induced apoptosis in chicken spleen but not involving Nrf2regulated antioxidant response. Ecotoxicol Environ Saf 145:503-510. https://doi.org/10.1016/j.ecoenv.2017.08.001

57. Dai M, Feng M, Liu D, Cao W, Liao M (2015) Development and application of SYBR Green I real-time PCR assay for the separate detection of subgroup J Avian leukosis virus and multiplex detection of avian leukosis virus subgroups A and B. Virol J 12:52. https://doi.org/10.1186/ s12985-015-0291-7

\section{Publisher's Note}

Springer Nature remains neutral with regard to jurisdictional claims in published maps and institutional affiliations.
Ready to submit your research? Choose BMC and benefit from:

- fast, convenient online submission

- thorough peer review by experienced researchers in your field

- rapid publication on acceptance

- support for research data, including large and complex data types

- gold Open Access which fosters wider collaboration and increased citations

- maximum visibility for your research: over $100 \mathrm{M}$ website views per year

At BMC, research is always in progress.

Learn more biomedcentral.com/submissions 